\title{
Balancing Private Rights and Public Policies: RECONCEPTUALIZING PROPERTY IN DATABASES
}

By Jacqueline Lipton ${ }^{t}$

\begin{abstract}
This Article presents a new paradigm for thinking about intangible property rights in response to recent criticism that information products such as databases should not be over-propertized. Analyzing the inherent problems with existing approaches, the Article concludes that creating private property rights in these intangible assets will not inevitably lead to commercial and social problems. On the contrary, legislatures can create private property rights that when accompanied by appropriate oversight and monitoring will preserve commercial markets and the public domain of information. Indeed, a new database law can use the concept of property as an organizing tool to properly balance private rights and the public policies. In developing this new approach to database protection, this Article examines the international debate on the creation of private property rights in databases. Furthermore, unlike previous models for sui generis database protection law based on copyright or trade secret law, the model in this Article draws on the principles underlying trademark and patent law in reaching a new solution.
\end{abstract}

(C) 2003 Jacqueline Lipton

$\dagger$ Assistant Professor, Case Western Reserve University School of Law; 11075 East Boulevard, Cleveland, Ohio 44106, USA; Email: JDL14@cwru.edu; Fax: + 1216 368 2086; B.A. (Melb), B.A. (Hons) (La Trobe), LL.B (Hons) (Melb), LL.M (Monash), LL.M (Cambridge), Ph.D. (Griffith), Barrister and Solicitor of the Supreme Court of Victoria and the High Court of Australia. The author would like to thank Professor Andrew Morriss, Professor Peter Gerhart, Professor Craig Nard, Professor George Dent, Professor Michael Heise, Professor Cynthia Ho, Professor Sara Nelson, and Professor Mark Lemley for their comments on earlier drafts of this Article, as well as Mark Davison and Catherine Colston for useful information about database law in the European Union. The author would further like to thank participants in the Second Annual Intellectual Property Scholars' Conference at Cardozo Law School, New York City, August 8-9, 2002 for their helpful comments, as well as the participants in the ISLAT/IASTED Third Annual Law and Technology Conference, Boston, November 6-7, 2002. Finally, the author would like to thank Amy Noss for her valuable research assistance. All views expressed herein and any errors or omissions are those of the author. 


\section{TABLE OF CONTENTS}

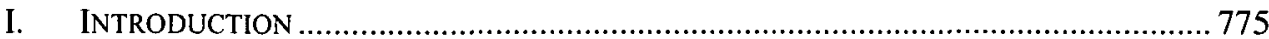

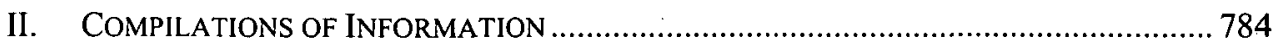

A. The Nature of Information Compilations and the Regulatory Impulse ........ 784

1. The Vulnerability of Compiled Information ....................................... 784

2. Enhanced Legal Protection For Compiled Information........................ 786

3. Refocusing the Debate on Database Protection................................... 788

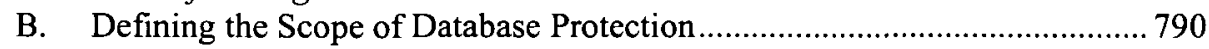

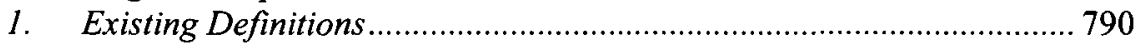

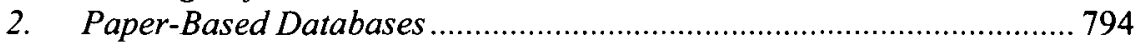

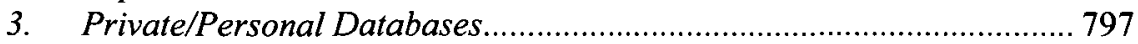

4. Scientific, Technical, and Educational Databases .............................. 797

5. A Proposed New Database Definition............................................... 799

C. Commercial Exploitation of Databases .................................................. 800

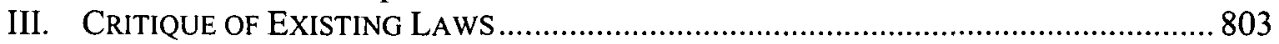

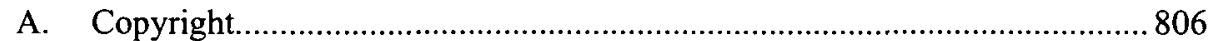

1. Copyrighting Databases: The Feist Decision................................... 806

2. International Criticism of the Feist Decision: Telstra v. Desktop Marketing Systems.......................................................................... 810

3. Limitations of Copyright Law in the Database Context ...................... 813

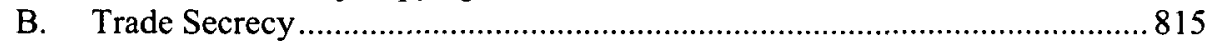

1. Basis of Trade Secret Law.................................................................... 815

2. The Secrecy Requirement ............................................................... 818

C. Sui Generis Database Protection Laws: Property Versus Tort ..................... 820

1. Existing Approaches to Sui Generis Database Legislation.................. 820

2. The Consumer and Investor Access to Information Bill ..................... 822

3. The E.U. Approach.................................................................... 824

4. The Current E.U. Framework As Adopted in the United Kingdom....... 825

5. Critiquing the E.U. Approach ........................................................ 829

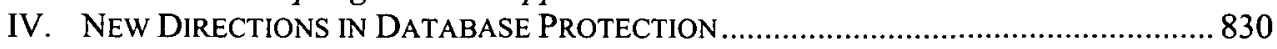

A. Elements for a Comprehensive Database Protection Law .......................... 831

B. Criteria for Protection........................................................................ 833

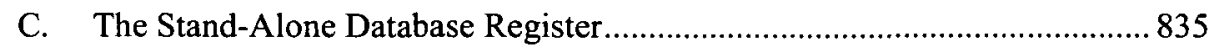

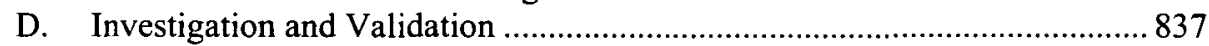

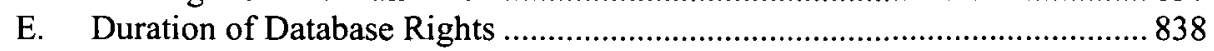

F. Permitted and Prohibited Activities in Relation to Database Rights ............. 841

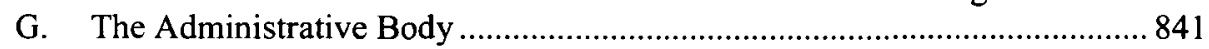

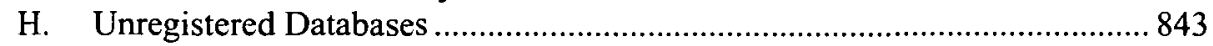

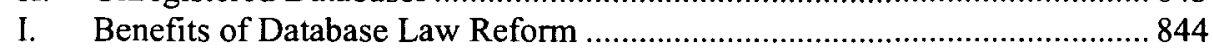

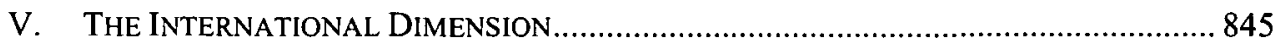

A. The International Picture on Database Protection ......................................8 845

B. The Role of International Legislative Cooperation .....................................846

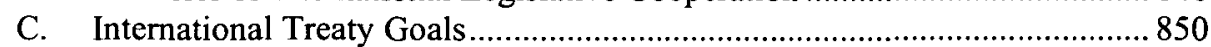

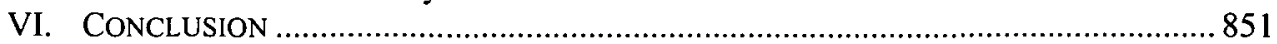




\section{INTRODUCTION}

In the general discussion over whether to recognize intellectual property rights in various areas of digital technology, the debate over proprietary rights in databases has raised many difficult questions. What should be the extent of the database rights? What are the ways in which these rights can be implemented? Can producers of databases claim these rights? Should they be able to claim these rights?

Databases span a wide range of fields. Some commercial and government databases contain consumer data-spending habits, ${ }^{1}$ health, insurance, or financial status. ${ }^{2}$ Other databases, some combining commercial and non-commercial uses, contain scientific, technological, or educational information. ${ }^{3}$ Some commercially valuable databases may form the core of a company's business operations in areas such as travel planning, ${ }^{4}$ stock brokeraging, ${ }^{5}$ and online shopping. ${ }^{6}$ Finally, some databases are relatively mundane compilations, such as phone books, but

1. Many major supermarket chains and other large department stores compile consumer spending information to enable targeted marketing. Allison Kidd, A Penny Saved, A Lifestyle Learned? The California and Connecticut Approaches to Supermarket Privacy, 4 N.C. J.L. \& TECH. 143, 144-45 (2002).

2. Private financial institutions and insurance companies maintain their own customer records, while governments may collect health records and credit reporting agencies financial information on a widespread basis. Robert W. Hahn \& Anne LayneFarrar, The Benefits and Costs of Online Privacy Legislation, 54 ADMIN. L. REV. 85, 107 (2002); Rick S. Lear \& Jefferson D. Reynolds, Your Social Security Number or Your Life: Disclosure of Personal Identification Information by Military Personnel and the Compromise of Privacy and National Security, 21 B.U. INT'L L.J. 1, 15 (2003).

3. These would include databases of profession-specific information such as LEXIS and Westlaw as well as more scientific and technical information. See Genomes OnLine Database, Integrated Genomics, Inc., at http://www.genomesonline.org/ (last visited July 24, 2003); Geographic Names Information System, U.S. Geo. Survey at http://geonames.usgs.gov/ (last visited July 22, 2003); NIST Scientific \& Technical Databases, Nat'l Inst. of Standards \& Tech., at http://www.nist.gov/srd/online.htm (last visited July 24, 2003).

4. Online travel agencies such as Expedia, Travelocity, and Orbitz maintain comprehensive databases of airline schedules and prices, hotel accommodations, car rental agencies, consumer trip planners, etc. See, e.g., Expedia, at http://www. Expedia. com.

5. Financial institutions and financial planning companies keep large databases of stock prices.

6. An obvious example involves the comprehensive databases maintained by Amazon.com involving consumer preferences, books, and other products in stock, consumer reviews, etc. 
may still have commercial value and raise questions about proprietary protection. $^{7}$

Some of these databases should have associated proprietary and quasiproprietary rights. ${ }^{8}$ Realistically, property rights probably cannot be avoided if the market demands them. Establishing property rights by applying the concept of property to databases should not lead inevitably, as some critics suggest, to unfair information monopolies. Rather, legislatures can use property rights as a tool to strike an appropriate balance between private and public interests in database information.

The structure and content of database law should clearly evidence its purpose: to serve the needs of commerce by giving artificial lead time ${ }^{9}$ to those who have invested time, effort, or financial resources in developing commercial databases. However, current debate ignores this purpose for the most part, focusing instead on the need for sui generis legislation protecting the contents of a database based on a copyright model. This misplaced focus on copyright models in the United States arises from perceived failings of copyright law to adequately protect databases in the wake of the Supreme Court's decision in Feist Publications v. Rural Telephone Service Co. ${ }^{10}$ In Feist, the Supreme Court held that only databases showing some degree of originality in the selection, arrangement, or organization of their contents could merit copyright protection. ${ }^{11}$ In reaching this holding, the Court rejected that the investment of time, effort, or money could justify protection. Because of Feist's holding, discussions about intellectual property rights in databases

7. Feist Publ'ns v. Rural Tel. Serv. Co., 499 U.S. 340 (1991) (holding that a white pages telephone directory was not protected under copyright law); see also ProCD, Inc. v. Zeidenberg, 86 F.3d 1447 (7th Cir. 1996) (upholding a shrinkwrap license prohibiting the copying of a digital telephone directory contained in commercial software).

8. There is no empirical evidence about the need for property rights in databases, but anecdotal evidence suggests that there may indeed be such a need in commerce. Justin Hughes, Political Economies of Harmonization: Database Protection and Information Patents 89-90 (Cardozo Law School, Public Law Research Paper No. 47, 2002), available at http://papers.ssrn.com/sol3/papers.cfm?abstract_id=318486 (last visited Aug. 24, 2003) (discussing the political and market forces behind the debates for database protection legislation in the United States and in other jurisdictions).

9. I base this Article's proposition on the argument that database producers deserve some legally-created "lead time" to exploit their work to overcome market failures that may otherwise arise because of the ease with which competition can now copy and disseminate information compiled by the original database producer. J.H. Reichman \& Pamela Samuelson, Intellectual Property Rights in Data?, 50 VAND. L. REV. 51, 145-58 (1997).

10. 449 U.S. at $359-60$.

11. Id. at 348 . 
tend to begin with assumptions derived from copyright law and relating to copying conduct.

This focus on copyright principles is significantly flawed. When applied to commercial databases, models based on copyright principles encourage the creation of overbroad private rights in large volumes of information. The European Union, for example, currently overprotects databases. ${ }^{12}$ Moreover, attempts to carve out fair use exceptions based on copyright law further complicate the application of copyright principles to digital databases. ${ }^{13}$ Thus, the focus of the debate must move away from models that draw mainly on copyright law.

In the United States, laws based on a hybrid of copyright and trade secret law known as the "tort/misappropriation model" have been proposed. ${ }^{14}$ The tort/misappropriation model still suffers from the legacy of copyright by creating a broad definition of a protected database followed by a list of vague fair use exceptions, but it may be preferable in some ways to pure copyright models. ${ }^{15}$ The advantage of a tort/misappropriation model is that it focuses on "commerce" and "unfair conduct in commerce"-principles better suited to database protection than copyright's focus on protecting artistic and creative works ${ }^{16}$ against

12. Catherine Colston, Sui Generis Database Right: Ripe for Review?, 3 J. INFO., L. \& TECH. 4, $\S \S 2.2,3.2$ (2001), at http://elj.warwick.ac.uk/jilt/01-3/colston.html (last visited Aug. 24, 2003); Reichman \& Samuelson, supra note 9, at 76-77.

13. Part of the difficulty is in clearly defining the scope of fair use exceptions to copyright infringement in the digital age. See 17 U.S.C. $\S 107$ (2000); MARK LEMLEY ET AL., 3 SOFTWARE AND INTERNET LAW, 109-10 (2d ed. 2003) (describing the difficulties courts have had in interpreting the fair use factors in copyright cases). These problems should not be carried over into any new database laws.

14. See discussion infra Parts II-IV. On suggestions for developing a database law modeled on a tort/misappropriation model drawing from the law of trade secrets, see Reichman \& Samuelson, supra note 9, at 80-81.

15. 17 U.S.C. $\S 107$ (providing a fair use defense to copyright infringement where copying is undertaken for "purposes such as criticism, comment, news reporting, teaching (including multiple copies for classroom use), scholarship, or research"). Consumer and Investor Access to Information Bill, H.R. 1858, 106th Cong. (1999). In determining whether a particular use is a fair use, courts take into account four factors:

(1) the purpose and character of the use, including whether such use is of a commercial nature or is for nonprofit educational purposes; (2) the nature of the copyrighted work; (3) the amount and substantiality of the portion used in relation to the copyrighted work as a whole; and (4) the effect of the use upon the potential market for or value of the copyrighted work.

17 U.S.C. $\$ 107$.

16. 17 U.S.C. $\$ 102$ (describing the subject matter of copyright in terms of various listed "original works of authorship"). 
unauthorized reproduction. ${ }^{17}$ Again, however, granting broad protections subject to fair use exceptions creates uncertainties and limits the utility of laws based on this model.

As explained in this Article, the better approach to database protection legislation is a model based on the underlying principles of trademark and patent registration. ${ }^{18}$ This model uses a combination of market and government regulation to replace the strongly market-focused approaches inherent in both the copyright and tort/misappropriation models. Legislation based on this model would create a government authority to oversee a register of database rights, applications for registration, compulsory licensing, and the release of certain database contents into the public domain. Ultimately, a legislature could empower the administrative authority to resolve disputes among database creators, their competitors, and those who seek access to the contents of a database.

In contrast to this regulation model, many commentators have argued that the state should avoid regulating commercial databases as intellectual property principally because they view less state regulation as generally better. ${ }^{19}$ For example, Professor Lawrence Lessig notes that in the twentieth century's global debate over whether the market or state is better suited to regulate the allocation and control of society's resources, the market has usually trumped the state. ${ }^{20}$ These victories were based on the belief that markets worked better than the state in regulating resources ${ }^{21}$ and that "whatever problems there are with the market, the problems with government are far more profound."22 Professor Lessig suggests that

17. 17 U.S.C. $\S 501$ prohibits violation of any of the exclusive rights of a copyright owner set out in the Copyright Act. These exclusive rights relate to reproduction and distribution, derivative works, and public performance. See also 17 U.S.C. $\S 106$.

18. For example, this new model would limit protection to bona fide commercial uses of databases in identified markets and incorporate a registration system for relevant rights in databases.

19. See, e.g., Regulation Without the State ... The Debate Continues (John Blundell \& Colin Robinson eds., 2000); Solveig Singleton, Self-Regulation: Regulatory Fad or Market Forces?, CATO WHITE PAPERS AND MISC. REPORTS, May 7, 1999 at http://www.cato.org/pubs/wtpapers/990507report.html; Ugnius Trumpa, Does State Regulation Protect Consumers?, THE FREE MARKET (Lithuanian Free Market Inst., Lithuania), Apr.-June 1998, at http://www.freema.org/NewsLetter/regulation/1998.2. state.phtml (last visited Aug. 27, 2003).

20. LaWrence Lessig, The Future of IdEAs: The Fate of the Commons in a CONNECTED WORLD 12 (2001).

21. Id.

22. Id. (discussing theory of Ronald Coase). 
certain resources should not be regulated at all, but should rather be left "free" ${ }^{23}$ in the First Amendment sense of the term. ${ }^{24}$

However, are these underlying assumptions are correct? Should the market trump the state in all contexts? How can we presume that the government will always cause more profound problems than the market when creating and regulating rights in information resources when we have functioning state-run regimes in trademark and patent law?

Despite the anti-regulatory sentiment, governments in many areas of law have traditionally overseen and monitored statutory property rights. ${ }^{25}$ Surprisingly, however, this governmental oversight has not spread to the regulation of intangible assets. ${ }^{26}$ If a government is prepared to create new digital information property rights, such as existing laws in the European Union and proposed legislation in the United States, ${ }^{27}$ it should also be prepared to take some control over the allocation and regulation of these property rights.

The information products market represents many important and competing interests. Because of the complex mixture of public and private interests in the information contained in databases, it is impertive that the government oversee the rights created in these databases. Market players seeking to commercially exploit databases obviously desire private property rights in databases. This desire for rights, however, must be balanced against competing public and private interests in database information. For example, individuals may have a privacy interest in personal information stored in certain databases like those compiling

23. Id.

24. Id. (Richard Stallman, who advocates that some information should be "free" in the sense of "free speech" rather than in the sense of "free beer").

25. See Bruce Yandle \& Andrew P. Morriss, The Technologies of Property Rights: Choice Among Alternative Solutions to Tragedies of the Commons, 28 ECOLOGY L.Q. 123,148 (2001) (arguing that statutory law creates a "strong incentive" for government involvement in a real property context).

26. Although some degree of government oversight is seen in traditional intellectual property law in the patent and trademark context, it has been lacking with respect to, say, property rights in copyright works in the digital age. Whereas patent and trademark applications are examined in detail prior to registration, copyright is very much asserted and commercially exploited at the right-holder's discretion. See discussion infra Part II.

27. Relevant legislative iniatives include: in the European Union, Council Directive 96/9/EC on the Legal Protection of Databases, 1996 O.J. (L 77) 20 [hereinafter E.U. Directive]; in the United States, the Collections of Information Antipiracy Bill of 1999, H.R. 354, 106th Cong. (1999), and the Consumer and Investor Access to Information Bill of 1999, H.R. 1858, 106th Cong. (1999). 
consumer spending habits. ${ }^{28}$ Consumers may have an interest in knowing information about products they purchase. Scientists, technologists, and educators have an interest in accessing database contents for noncommercial teaching and research. ${ }^{29}$

An important reason for advocating governmental rather than market force regulation of these property rights is that pure market control may not be able to properly regulate a market where the market players that are lobbying the legislatures to create statutory private property rights are the same players seeking to subsequently exploit the rights. If the government must create the relevant private property rights, a market in those rights might well be unable to regulate itself without some government assistance. $^{30}$

Furthermore, markets in information products tend to be valuable and volatile. $^{31}$ They also often involve many competing interests that the market players are not interested in protecting. ${ }^{32}$ Therefore, some government oversight may be needed to prevent unjustifiable information monopolies and to balance competing rights and interests in information for the good of commerce and society.

Finally, many information products, including some databases, are purely commercial. As seen recently with digital copyrighted works, market forces have a limited ability to deal with non-commercial aspects

28. Ann Bartow, Our Data, Ourselves: Privacy, Propertization, and Gender, 34 U.S.F. L. REV. 633, 633-34 (2000); Jessica Litman, Information Privacy/Information Property, 52 STAN. L. REV. 1283, 1284 (2000).

29. J.H. Reichman \& Paul F. Uhlir, Database Protection at the Crossroads: Recent Developments and Their Impact on Science and Technology, 14 BERKELEY TECH. L.J. 793, 809-10 (1999).

30. See Yandle \& Morriss, supra note 25, at 164-67.

31. See Bartow, supra note 28 , at 647 (on the value of information markets in the digital age, particularly in the targeted marketing context); Litman, supra note 28 , at 1290 (noting value of information markets and that some groups, notably consumers, often lose control over information in such markets); Pamela Samuelson et al., A Manifesto Concerning the Legal Protection of Computer Programs, 94 COLUM. L. REV. 2308, 2314, 2338 (1994) (characterizing software as an information product that is more vulnerable than traditional manufactured goods to market-destructive appropriations because of the applied industrial know-how born on or near the surface of software products).

32. For instance, how can we protect personal privacy rights and fair uses of information when private property interests invade the "information domain"? See Yochai Benkler, Free as the Air to Common Use: First Amendment Constraints on Enclosure of the Public Domain, 74 N.Y.U. L. REV. 354, 360-64 (1999); Litman, supra note 28 , at $1306-09$. 
of these products. ${ }^{33}$ For example, the copyright industry successfully lobbied both for increased copyright protection terms ${ }^{34}$ and amendments to the Copyright Act that support technological protection for digital copyright. ${ }^{35}$ In these cases, market players have shown little interest in preserving the public domain or fair use rights. ${ }^{36}$

Regardless of whether particular governments take an interest in creating property rights in information, some form of property or quasiproperty in information will undoubtedly develop if that information has commercial value and market players desire to exploit it. ${ }^{37}$ As seen in digital information markets, market players have used contract and technological protection to control information for commercial exploitation despite the lack of statutory or judicially-created property rights in information. ${ }^{38}$ Thus, we should not necessarily oppose the

33. See Benkler, supra note 32, at 411; Jacqueline Lipton, Copyright in the Digital Age: A Comparative Survey, 27 RUTGers COMPUTER \& TECH. L.J. 333, 358 (2001) [hereinafter Lipton, Comparative Survey]; David Nimmer, A Riff on Fair Use in the Digital Millennium Copyright Act, 148 U. PA. L. Rev. 673, 714 (2000); Pamela Samuelson, Intellectual Property and the Digital Economy: Why the Anti-Circumvention Regulations Need to be Revised, 14 BERKELEY TECH. L.J. 519, 537-46 (1999).

34. Sonny Bono Copyright Term Extension Act §102, 17 U.S.C. § 302 (2000) [hereinafter CTEA]. A challenge to the validity of this legislation was argued and defeated before the Supreme Court in Eldred v. Ashcroft, 537 U.S. 186 (2003).

35. Digital Millennium Copyright Act (codified as amended in scattered sections of 18 U.S.C. (2000)) [hereinafter DMCA]. Note that these provisions may not prove effective against some hackers.

36. Universal City Studios, Inc. v. Reimerdes, 111 F. Supp. 2d 294, 323-24 (S.D.N.Y. 2000), aff'd, 273 F. 3d 429 (2d Cir. 2001) (holding that the fair use provisions of the Copyright Act cannot be used as a defense to an infringement of the DMCA's anticircumvention and anti-trafficking provisions as this was not the legislative intent of 17 U.S.C. §1201(a)); Benkler, supra note 32, at 356-57; Nimmer, supra note 33, at 702-10; Samuelson, supra note 33, at 537-46; John R. Therien, Exorcising the Specter of a "PayPer-Use" Society: Toward Preserving Fair Use and the Public Domain in the Digital Age, 16 BerkeLEY TECH. L.J. 979, 1008-10 (2001) (writing about concerns that the DMCA will over-propertize digital information if courts do not take an adequate stance on protecting fair uses).

37. Raymond Nimmer, 1 THe Law of COMPUTER TeChNology, \ 3.02[1] (3d ed. 1997) (noting that trade secrets are described as "property" by American courts and legislators, despite the fact that they do not evidence significant elements from traditional property theory, precisely because of the need for markets effectively to transact with the relevant information); Litman, supra note 28, at 1290-93 (making similar observations in the information property context).

38. ProCD, Inc. v. Zeidenberg, 86 F.3d 1447, 1455 (7th Cir. 1996) (upholding shrinkwrap license in a "pure" information product in the form of a digital telephone directory); William W. Fisher III, Property and Contract on the Internet, 73 CHI.-KENT L. REv. 1203, 1249 (1998) (observing how contract and technological measures are taking over from reliance on statutory property rights in protecting information products 
creation of property rights in information by courts and legislatures so long as these institutions are vigilant about limiting the rights in ways that support the realistic commercial needs of rights-holders without encroaching unnecessarily into the public domain of information and ideas, or the competing private interests in relevant information, such as personal privacy rights.

Many of the arguments made in the following discussion of property rights in databases may become broadly applicable to other parts of intellectual property law, notably to U.S. copyright law in the wake of the enactment of the Digital Millennium Copyright Act ("DMCA"). ${ }^{39}$ By focusing here on the potential of collections of information to comprise information property rights, the kinds of limitations or regulations that may operate in this context, and the appropriate amount and nature of government oversight, this Article may provide a useful guide for thinking about the law relating to future digital property rights.

Part II considers the nature of a compilation of information, or "database," and attempts to identify and significantly restrict the types of databases likely to warrant protection under any new private property regime in the United States. The criteria for legislative protection arise from the realistic commercial objectives of rationally self-interested database producers. ${ }^{40}$ Any new database protection law should be clearly addressed to these objectives, and should not operate any more broadly than necessary to achieve these ends. Furthermore, Part II argues that in defining the appropriate scope of the private property rights with respect to the commercial objectives of database producers, Congress should not make the mistake of concluding that the market alone should regulate the commercial exploitation of those rights. The government should be ready to take on a significant monitoring and controlling role, particularly where property rights in information per se are implicated. ${ }^{41}$

from unauthorized interference, and in transacting with information); Michael $\mathrm{J}$. Madison, Legal-Ware: Contract and Copyright in the Digital Age, 67 FoRDHAM L. REV. $1025,1054-76$ (1998) (observing how contractual licenses are overtaking proprietary copyrights as the mechanism for commercial exploitation of valuable digital information products).

39. See DMCA, supra note 35; Benkler, supra note 32, at 414-15; Lipton, Comparative Survey, supra note 33, at 339-44; Nimmer, supra note 33 , at $674-75$; Samuelson, supra note 33, at 558.

40. See Mary Maureen Brown, Robert M. Bryan, \& John M. Conley, Database Protection in a Digital World, 6 RiCH. J.L. \& TECH. 2, I 35 (1999), at http://law. richmond.edu/jolt/v6il/conley.html.

41. See Litman, supra note 28 , at $1294-95$ (describing the downsides of creating private property rights in information). 
Part III turns to some of the major shortcomings of existing laws in protecting private property rights in databases, notably copyright law and trade secret law. It also critically examines models for new sui generis database protection legislation in the United States and European Union.

Part IV suggests new approaches to sui generis laws that deal with the creation and commercial exploitation of property rights in databases. The new approaches draw significantly from those aspects of trademark and patent law that require some government oversight of private property rights in commercially valuable information products.

Part V considers some of these suggestions within a broader international context because of the increasingly global nature of information commerce. There is some concern that U.S. legislation could end up clashing with the European Union's Directive on the Legal Protection of Databases ("E.U. Directive"), ${ }^{42}$ which is already in place throughout the European Union and which could disadvantage American businesses abroad. ${ }^{43}$ The E.U. Directive has been criticized for creating too much protection for databases and too little protection for public interests in their contents. ${ }^{44}$ The United States currently has a chance to lead the way in effective and efficient database protection legislation at the international level; however, Congress must act quickly, before the E.U. position becomes entrenched as the global standard.

Finally, Part VI presents some conclusions about the need for a database protection model that can effectively balance private rights and public interests in database contents, and the present opportunity for the United States to take a leadership role in harmonizing this increasingly important aspect of intellectual property law across international lines.

42. E.U. Directive, supra note 27.

43. As will be apparent from the following discussion, many would argue that the E.U. approach to database protection legislation has been a failure, or at least a highly questionable legislative measure, partly because of the lack of clear delineation of the rights in question by the government and arguably also because of the lack of ongoing government oversight in relation to the commercial exploitation of those rights.

44. Colston, supra note $12, \S \S 3.2-3.3$. Unfortunately, a number of models for American database protection legislation to date evidence similar problems. Reichman \& Samuelson, supra note 9, at 77. 


\section{COMPILATIONS OF INFORMATION}

\section{A. The Nature of Information Compilations and the Regulatory Impulse}

\section{The Vulnerability of Compiled Information}

In an age in which information is more readily available and more valuable than ever before, products made up of pure information are also more vulnerable in commerce. ${ }^{45}$

Some information products such as customer lists, spending profiles of particular people, or the television viewing preferences of particular groups may contain personal information. ${ }^{46}$ Other products such as business directories, event calendars, timetables, product catalogues, or supplier and distributor lists may contain more impersonal information. These products have always had undeniable commercial value, particularly for marketing and tailoring new products and services to better match consumer needs. ${ }^{47}$ Today, an unprecedented amount of information can be collected, collated, and re-presented in accessible, flexible ways in order to meet particular user needs. For example, a user may search airline databases for flights based on a specified itinerary, price range, and time; and then arrange the results according to the user's priorities. ${ }^{48}$ However, as user flexibility expands, the ease with which information can be accessed electronically and perfectly copied by commercial competitors is also increasing. ${ }^{49}$ This presents a challenge for intellectual property law.

Traditional intellectual property is poorly suited to protecting database products. ${ }^{50}$ Patent law will not work: an information product's value is in the information per se, not in any patentable invention. Under copyright law, the selection or arrangement of a database's contents is often not

45. COMM. To Study Global Networks \& Local Values, Nat'L Research Council, Global Networks and local Values: A Comparative look at GeRMANY AND THE UNITED StATES 176 (2001); Rex Y. Fujichaku, The Misappropriation Doctrine in Cyberspace: Protecting the Commercial Value of "Hot News" Information, 20 U. HAW. L. REV. 421, 428 (1998); Samuelson et al., supra note 31 , at 2337-38.

46. See Litman, supra note 28 , at 1283-84.

47. See Bartow, supra note 28 , at 643-50.

48. Jonathan A. Weininger, Trademark Metatagging: Lanham Act Liability or Pareto Optimality? 23 WHITTIER L. REV. 469, 473 (2001) (explaining use of search engines on the Internet in terms of accommodating specific user requests).

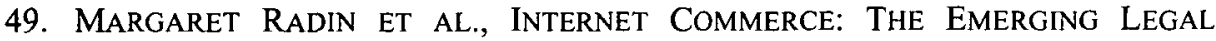
FRAMEWORK 629-30 (2002).

50. Id. 
sufficiently original to warrant protection. ${ }^{51}$ In fact, the value of a commercial online database often lies in the very comprehensiveness and non-selectivity of its contents. ${ }^{52}$

Furthermore, trade secret law will only protect a commercial database if everyone who has access to the database, both authorized and unauthorized, has agreed to a confidentiality agreement enforceable in both national and foreign courts. ${ }^{53}$ This involves high transaction costs, making this form of protection impracticable. Thus, patent, copyright, and trade secret law cannot effectively protect a producer's interest in a commercial database.

True, technological protection measures can serve as an interim measure to minimize unauthorized access to compilations of information. ${ }^{54}$ However, such measures must constantly be updated or risk computer hackers cracking the technology and accessing or disseminating the protected information. ${ }^{55}$ Laws, such as the anti-circumvention and anti-device provisions of the DMCA, can prohibit unauthorized cracking of encryption codes. ${ }^{56}$ But legal enforcement may, in many cases, be the equivalent of shutting the barn door after the horse has bolted. ${ }^{57}$ By the

51. See Feist Publ'ns v. Rural Tel. Serv. Co., 499 U.S. 340, 340 (1991) (rejecting the "sweat of the brow" doctrine).

52. Wesley L. Austin, A Thoughtful and Practical Analysis of Database Protection Under Copyright Law, and a Critique of Sui Generis Protection, 3 J. TECH. L. \& POL'Y 3, 58 (1997), available at http://journal.law.ufl.edu/ techlaw/3-1/austin.html (last visited Aug 30, 2003); Brown, Bryan, \& Conley, supra note 40, 46.

53. See Kewanee Oil Co. v. Bicron Corp., 416 U.S. 470, 475 . (1974) ("The protection accorded the trade secret holder is against the disclosure or unauthorized use of the trade secret by those to whom the secret has been confided under the express or implied restriction of nondisclosure or nonuse.")

54. Jacqueline Lipton, Protecting Valuable Commercial Information in the Digital Age: Law, Policy and Practice, 6 J. TECH. L. \& POL'Y 2, 26-28 (2001), available at http://grove.ufl.edu/ techlaw/vol6/Lipton.htm (last visited Aug. 24, 2003) [hereinafter Lipton, Commercial Information].

55. NAT'L Research Council, A Question of Balance: Private Rights and

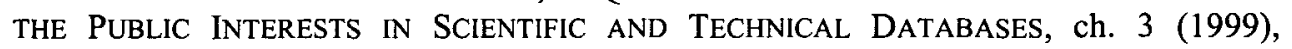
available at http://www.nap.edu/html/question_balance/ch3.html (last visited Aug. 24, 2003).

56. DMCA, supra note 35, 17 U.S.C. $\S \S 1201(a)(1)(A), 1201(a)(2), 1201(b)(1)$ (2000).

57. For example, monetary compensation may be inadequate if damages are difficult to quantify or if the defendant is an impecunious computer hacker. Injunctions may also prove pointless to stop the dissemination of a decryption technology once the code is in the public domain. The spread of hacking code on the Internet can be rapid and global, and it may prove impossible for a court to grant an injunction that has any hope of stopping people the world over from using the decryption measure to access the relevant 
time a court hears a case, the damage has already been done and whatever remedy the court may order would be inadequate to repair the damage. ${ }^{58}$

\section{Enhanced Legal Protection For Compiled Information}

Current discussion among lawmakers and members of the legal community shows a need for legislation to protect information compilations. $^{59}$ Given the value and vulnerability of information compilations, the next steps are to clearly identify the kinds of compilations that might merit some form of enhanced legal protection and then to determine what shape such protection should take. This is a timely and difficult issue that goes to the heart of the tensions in existing intellectual property law, both within the United States and internationally. ${ }^{60}$ The debate will be most fruitful if conducted with this broader context in mind.

Notably, there is no empirical evidence available about actual or potential market failures in this area. Thus, some argue for foregoing any new legislation at all. This would allow the market to sort out the relevant issues using contractual provisions ${ }^{61}$ and technological protection

work(s). A federal district court made this point in Reimerdes. Universal City Studios, Inc. v. Reimerdes, 111 F. Supp. 2d 294, 344 (S.D.N.Y. 2000). The judge granted an injunction prohibiting the defendants from maintaining links on their websites to software that decrypted technical protection measures designed to prevent DVD copying, as well as links to other websites that maintained this software. Id. at 343 . The judge was prepared to grant the injunction as a matter of principle, but noted that it may not be of much practical comfort to the plaintiff movie studios for the above reasons. Id. at 344-45. The decision was recently upheld on appeal. See Universal City Studios, Inc. v. Corley, 273 F.3d 429 (2d Cir. 2001), available at http://www.nyls.edu/samuels/copyright/ beyond/cases/reimerdesapp6.htm (last visited June 18, 2002).

58. Reimerdes, 111 F. Supp. $2 \mathrm{~d}$ at 344.

59. Telstra Corp. v. Desktop Mktg. Sys. Pty Ltd. (2001) F.C.A. 612, ๆ 83, aff'd, (2002) F.C.A.F.C. 112 (Austl.) (making Australian law the opposite of American law under Feist with respect to copyright in non-original databases, which may evidence the need to rethink database protection on a more global scale to achieve some measure of international harmonization), available at http://www.austlii.edu.au/au/cases/cth/ federal_ct/2001/612.html (last visited Aug. 24, 2003); Brown, Bryan, \& Conley, supra note 40, ๆf 61-64; Reichman \& Samuelson, supra note 9, at 55.

60. David Lange et al., Intellectual Property: Cases and Materials, Ch. 1 (1998); Reichman \& Samuelson, supra note 9, at 52-53 (discussing the traditional distinction between what is protected by which particular form of intellectual property).

61. Ronald MANN \& JaNE WinN, Electronic COMMERCE 184-93 (2002); Margaret Radin, Online Standardization and the Integration of Text and Machine, 70 FORDHAM L. REV. 1125 (2002), reprinted in RADIN ET AL., supra note 49, at 362-65. 
measures ${ }^{62}$ while avoiding the potential danger of database protection legislation-a detrimental effect on the public domain of information.

However, leaving information protection of online databases to the market also involves certain risks. Laws now support "clickwrap" and "shrinkwrap" licenses of electronic information products. ${ }^{63}$ They also support the widespread use of digital rights management: technical encryption measures that prevent access to certain electronically stored information. ${ }^{64}$ Strengthened by these laws, market players that tend to have their own commercial interests at heart are unlikely to spend time and resources to implement systems to protect competing interests.

Designing a new database model that uses property rights to limit a database producer's ability to create market monopolies may be the most effective way to prevent database makers from using contractual and technological measures to create property rights that are impervious to any competing uses of the information. ${ }^{65}$

In today's global trading environment, ${ }^{66}$ there is little point in enacting piecemeal new legislative measures that differ significantly between jurisdictions. Moreover, any such legislative initiatives must not destroy the current policies underlying patent, copyright, and trade secret law both within and among jurisdictions. For intellectual property law to remain a cohesive and useful system, each new legislative development must further the overriding aims and objectives of the law. ${ }^{67}$

62. RADIN ET AL., supra note 49 , ch. 11 (providing an overview of technological protection measures).

63. See, e.g., UNIF. COMPUTER INFO. TRANSACTIONS ACT $\S 209$ (2001) [hereinafter UCITA]. UCITA has so far met with limited success in being adopted by state legislatures); see also ProCD, Inc. v. Zeidenberg, 86 F.3d 1447, 1447 (7th Cir. 1996); MANN \& WINN, supra note 61, at ch. 4; RADIN ET AL., supra note 49, at 299-342; Madison, supra note 38, at 1049-54.

64. See, e.g., DMCA, supra note 35, 17 U.S.C. $\S \S 201(\mathrm{a})(1)(\mathrm{A}), 1201(\mathrm{a})(2)$, 1201(b)(1).

65. Julie Cohen, DRM and Privacy, 18 BERKELEY TECH. L.J. 575, 608-09 (2003) (describing ways in which public policies have trumped contractual restrictions in the past, and noting that the same could occur in relation to digital rights management technologies coupled with tight contractual restrictions on information access; that is, the government could impose legislation that overrides the use of technologies and contracts that restrict access to information in certain circumstances).

66. Matters of international harmonization in this area are taken up in more detail in the final part of this Article.

67. Jeffrey C. Wolken, Just the Facts, Ma'am. A Case for Uniform Federal Regulation of Information Databases in the New Information Age, 48 SYRACUSE L. REV. 1263, 1294-98 (1998). 
However, it is equally important that new legislative initiatives actually be new. To date, the debate over intellectual property protection for databases has suffered from being too heavily focused on copyright models of database protection. New initiatives in database protection law must transcend the constraints of the copyright models and focus instead on identifying and addressing the realistic needs of commerce and public policy on compiled information.

In this context, moves toward new legislation must tackle, with specific reference to the types of information, the complex practical and theoretical questions surrounding the creation of new property or quasiproperty rights. Important issues, for example, arise about using law to commodify compilations of information that is personal or that has significant educational, scientific, or technical applications. Furthermore, moves toward creating new law must be sensitive to concerns about freedom of information, privacy, ${ }^{68}$ the needs of scientific and educational communities, ${ }^{69}$ and the cultural differences that can underlie attitudes toward these issues in different jurisdictions. ${ }^{70}$

Furthermore, new legislative initiatives must discard the misplaced focus on the tension between property and tort/misappropriation models that has characterized the debate so far. Those that favor the latter model tend to do so because it does not expressly advocate property rights in information. ${ }^{71}$ However, this distinction between the two models is flawed: both models involve property to some degree because something, property or quasi-property, must be the subject of the misappropriation.

\section{Refocusing the Debate on Database Protection}

Assuming a need for legislative action, we must confront the problem that recent approaches to database protection legislation, in both the European Union and the United States, have been born out of perceived failings of copyright law to adequately protect rights in commercially valuable databases and compilations. Thus, these approaches have

68. See Bartow, supra note 28 , at 634 ; Lipton, Comparative Survey, supra note 33 , at $364-65$.

69. See Paul A. David, A Tragedy of the Public Knowledge 'Commons'? Global Science, Intellectual Property and the Digital Technology BOOMERANG 4-7 (Oxford IP Research Centre, Working Paper No. 04/00, 2000), available at http://www.oiprc.ox.ac.uk/EJWP0400.html (last visited Aug. 24, 2003).

70. For example, the European Union has stronger privacy rights than the United States. See MANN \& WINN, supra note 61, at 184-93.

71. Other differences between the two models include the duration of rights granted in information products, and the basis for calculation of damages for wrongful duplication or dissemination of protected information. 
unproductively focused on modifying existing copyright models to suit database protection. ${ }^{72}$

It would be more useful to refocus the discussion on the types of databases that require legal protection and how best to achieve such protection, being mindful of the need to balance any newly created rights in databases against competing public and private interests in information.

First-generation proposals for database legislation should demonstrate restraint since it is generally easier to expand the reach of a law that initially achieves too little protection than it is to restrict the operation of a law that initially creates too much. ${ }^{73}$ The right balance may come from thinking about using intangible property law to promote commerce rather than the expression of ideas. This would require shifting to models of intellectual property law historically developed to serve the needs of commerce, such as registered trademarks and trade secrets, away from those that originally served more artistic/expressive purposes, such as the law of copyright. ${ }^{74}$ This is not to suggest that markets should necessarily be the sole source of regulation of such rights, rather that laws creating such rights should focus on supporting information commerce as a primary objective.

Anglo-American copyright law has a significant commercial focus when compared with traditional European models of copyright law. ${ }^{75}$

72. The E.U. Directive, for example, takes the copyright approach of creating a relatively broad intellectual property right that will endure for a fixed term of years, then carving fair use type exceptions out of the right. E.U. Directive, supra note 27, at 20. Some Bills introduced into the U.S. Congress have also taken this approach. An example is the Collections of Information Antipiracy Act, H.R. 354, 106th Cong. (1999), which will be discussed in more detail infra. Even those approaches that do not expressly create a broad proprietary right tempered with fair use exceptions, do envisage at least an implied property right, again subject to fair use exceptions. See, e.g., Consumer and Investor Access to Information Act, H.R. 1858, 106th Cong. (1999). This will also be discussed infra. All these models assume that the market will largely regulate itself once the relevant rights and statutory prohibitions have been enacted.

73. Wolken, supra note 67, at $1297-98$.

74. The original purpose of copyright was to protect artists and artistic, literary, dramatic, and musical works, rather than to protect commerce. DEBORAH BOUCHOUX, Intellectual Property: The law of Trademarks, Copyrights, Patents, and TRADE SECRETS 133-38 (2000). Copyright has clearly been used to enhance commerce, particularly in recent years. However, the underlying model of the law is perhaps less commercially focused than, say, trademark law. Even the definition of a trademark draws heavily on commercial concepts and "trademark" is defined in relation to its use in commerce. See 15 U.S.C. $\$ 1127$ (2000).

75. See Gilliam v. ABC, 538 F.2d 14, 24 (2d Cir. 1976); U.S. Pat. \& Trademark OFF., REPORT OF THE WORKING GROUP ON INTELleCtUAL PROPERTY RIGHTS: INTELleCtuAl PROPERTY AND THE NATIONAL INFORMATION INFRASTRUCTURE 133-34 
However, Anglo-American copyright law still protects "works of authorship" 76 as opposed to the purely commercial subject matter of trademark law and trade secret law. As the subject matter of a new law, commercial databases seem to be more analogous to trademarks and trade secrets than they are to copyrights.

Using copyright structures as the basis for new models of database protection law introduces several problems. First, creating broad property rights with vague fair use exceptions is not suited to the needs of commercial database producers or to those claiming access rights in database contents. ${ }^{77}$ Furthermore, besides the simple registration process not even required to claim copyright protection, ${ }^{78}$ copyright law calls for little government oversight of the copyright's commercial exploitation or of exploitation that might adversely affected particularly vulnerable classes of copyright users. ${ }^{79}$

This might be an appropriate approach for copyright regulation in the digital age, but it is clearly not the right approach for regulating nonoriginal, non-creative compilations of information. Although a database producer may be entitled to some proprietary rewards for the expenditure of time, effort, or resources in compiling a commercially valuable database, the nature of the resulting asset calls for a private property regime that includes significant limitations on associated property rights, and some government oversight of the creation and exploitation of those rights.

\section{B. Defining the Scope of Database Protection}

\section{Existing Definitions}

One of the first problems in developing appropriate sui generis database protection law is to suitably define a "compilation of information" or "database." The definition should be limited to serving the

(Sept. 1995), available at http://www.uspto.gov/web/offices/com/doc/ipnii/lawcopy.pdf (last visited Aug. 7, 2003).

76. 17 U.S.C. $\S 102(a)(2000)$.

77. In fact, this traditional copyright scheme is increasingly unsuited to copyright holders and those seeking access to copyright works in the digital age. See Raymond Shih Ray Ku, The Creative Destruction of Copyright: Napster and the New Economics of Digital Technology, 69 U. CHI. L. REV. 263, 322-24 (2002).

78. The United States is in the minority of countries that actually have a copyright register. COPYRIGHT OFFICES WORLDWIDE, United Kingdom Intellectual Property Website, http://www.intellectual-property.gov.uk/std/resources/copyright/offices_world wide.htm (last visited Aug. 15, 2003).

79. See Benkler, supra note 32 , at 427 ; Nimmer, supra note 33 , at 693-99; Samuelson, supra note 33, at 537-546. 
legislation's aims: balancing the commercial needs of database producers with public policy concerns about over-commodifying information. Existing models of database protection law have tended to include a definition of database much broader than required and largely derived from similar definitions in copyright law. ${ }^{80}$ Adopting a more restricted definition of database can simplify new legislation by automatically limiting the rights derived from the defined item to relevant commercial activities. Moreover, such an approach minimizes the need to engage in a protracted debate about fair uses or permitted activities that we might otherwise wish to except as a matter of public policy from the activities prohibited under the legislation. If the definitions and associated rights are more tightly focused initially to protect limited commercial activities involving databases, then there is less need to create detailed fair use provisions, which tend to be problematic in both practice and theory. ${ }^{81}$

Existing laws that attempt to define the term "database" include the E.U. Directive and, in the United States, the Collections of Information Antipiracy Bill of 1999 ("Antipiracy Bill") $)^{82}$ and the Consumer and Investor Access to Information Bill of 1999 ("Consumer and Investor Access Bill") ${ }^{83}$ A look at these definitions suggests some directions for a more tailored approach. ${ }^{84}$

The E.U. Directive currently defines a database as "a collection of independent works, data or other materials arranged in a systematic or methodical way and individually accessible by electronic or other

80. "Compilation" (rather than "database") is defined in the U.S. copyright legislation broadly as "a work formed by the collection and assembling of preexisting materials or of data that are selected, coordinated, or arranged in such a way that the resulting work as a whole constitutes an original work of authorship." The term "compilation" includes "collective works." 17 U.S.C. $§ 101$. In the United Kingdom, the definition of "database" in the copyright legislation is arguably even broader. It encompasses "a collection of independent works, data, or other materials which (a) are arranged in a systematic or methodical way and (b) are individually accessible by electronic or other means." Copyright, Designs, and Patents Act, 1977, § 3A(1) (Eng.) [hereinafter CDPA].

81. See MARShall LeafFer, Understanding COPYRIGHT LaW 428 (3d ed. 1999); DAVID, supra note 69, at 5-6.

82. H.R. 354, 106th Cong. (1999).

83. H.R. 1858, 106th Cong. (1999).

84. Terms such as "database," "compilation," and "collection of information" have been defined variously, both colloquially and in legislation, throughout the world. For ease of reference, this discussion uses the term "database" in a generic sense to refer to all compilations or collections of information about which Congress may consider legislating. 
means." 85 This definition tracks the wording of a proposed World Intellectual Property Organization ("WIPO") treaty on database protection that never entered into force. ${ }^{86}$

Definitions of database or equivalent terms in proposed U.S. legislation have been a little more detailed. For example, the Consumer and Investor Access Bill defines "database" as:

[A] collection of discrete items of information that have been collected and organized in a single place, or in such a way as to be accessible through a single source, through the investment of substantial monetary or other resources, for the purpose of providing access to those discrete items of information by users of the database. However, a discrete section of a database that contains multiple discrete items of information may also be treated as a database. ${ }^{87}$

The reference here to a substantial investment of monetary or other resources derives from the idea that a sui generis database right should protect those databases in which producers make a substantial investment but which do not meet the standards of originality or creativity required by copyright law. ${ }^{88}$ Absence of the investment criterion in the E.U. Directive's definition of database does not mean that it is irrelevant to E.U. law. Rather, the Directive addresses the issue in Article 7(1), where it creates a sui generis database right. Likewise, Rule 13(1) of the Copyright and Rights in Databases Regulations 1977 (Eng.) establishes an investment criterion.

Thus, overall the Consumer and Investor Access Bill takes a similar approach to the E.U. Directive in how it defines a database. However, the U.S. bill uses "items of information" to describe the likely contents of a database whereas the E.U. Directive refers to "works, data or other materials." This appears to mean that the European Parliament and Council of Ministers had a broader array of items in mind than the drafters of the Consumer and Investor Access Bill, as the latter law would only cover a collection of discrete items of information, such as a list of customers, as opposed to an electronic library of, say, copyright works,

85. E.U. Directive, supra note 27, art. 1(2).

86. World Intellectual Property Organization [hereinafter WIPO], Draft Treaty on Intellectual Property in Respect of Databases 2(i) (1996) (on file with the author), available at http://www.wipo.org/eng/diplconf/6dc_sta.htm (last visited Sept. 26, 2001) [hereinafter WIPO, Draft Treaty].

87. H.R. $1858 \S 101(1)$.

88. See discussion of Feist case supra Part II.A. 
such as books or journal articles (for example, LEXIS or Westlaw). This argument is bolstered by the definition of "information" in section 101(3) of the bill: "[F]acts, data, or any other intangible material capable of being collected and organized in a systematic way, with the exception of works of authorship."

The idea behind this language is presumably that compilations of works of authorship are covered by section 103 of the Copyright Act and need not receive double protection as a result of any new database protection legislation enacted in the United States. ${ }^{90}$ However, this argument is not particularly convincing, as compilations of facts or data are also protected by section 103 . This suggests that the drafters of the copyright legislation saw no need to distinguish between the two types of compilations. On the other hand, both the customer list and the electronic library would meet the definition of database under European Union law, as the definition of the term in the E.U. Directive includes collections of "works" and "other materials" as well as "items of information."

Turning, then, to the definitions of "collection of information" and "information" found in section 2 of the Antipiracy Bill, which, if adopted, would add a new section 1401 to Title 17 of the United States Code ("U.S.C.") on copyright. Sequential drafts of this bill have put forth several versions of the definition of "collection of information," "the most recent of which is:

[I]nformation that has been collected and has been organized for the purpose of bringing discrete items of information together in one place or through one source so that persons may access them. The term does not include an individual work which, taken as a whole, is a work of narrative literary prose, but may include a collection of such works. ${ }^{92}$

89. H.R. $1858 \S 101(3)$ (emphasis added).

90. See supra note 80 . A "collective work" is defined as, "a work, such as a periodical issue, anthology, or encyclopedia, in which a number of contributions, constituting separate and independent works in themselves, are assembled into a collective whole." 17 U.S.C. $§ 101$ (2000).

91. This Bill evidences a preference of the drafters for the "collection of information" terminology over the database terminology used in the E.U. Directive.

92. H.R. 354, 106th Cong., $§ 1401$ (1) (1999). This version of the Bill, dated October 8,1999 , is an amended version of the original Bill introduced into the House on January 19,1999 . The main difference in the definition of "collection of information" between the two versions is the inclusion of the second sentence of the definition in the amended version of the Bill, presumably to clarify that the legislation would not override the operation of existing copyright law in relation to narrative literary works. 
This language clearly contemplates that both compilations of information/facts and compilations of works will qualify for protection under the new law. Yet an individual work will not, instead attracting copyright protection as a "literary work.",93

The Antipiracy Bill also defines "information" as "facts, data, works of authorship, or any other intangible material capable of being collected and organized in a systematic way." 94 Note the similarity between this approach to the idea of "information" or "data" and that comprised in the E.U. Directive. Here, again, a broad brush definition indicates that a database might comprise electronic libraries of literary works as well as more basic lists of information.

Although these different legislative models vary somewhat in their approaches to defining a database or compilation of information, they all arguably craft their definitions much broader than necessary. If these laws were designed to create limited database rights that encourage commercial innovation and exploitation, why do the initial definitions fail to distinguish between different types of databases? The definitions in any new legislation should identify and cover only those databases created for exploitation in identifiable commercial markets.

\section{Paper-Based Databases}

The recent, rapid growth of e-commerce and other online activity has revolutionized the role of databases in business and other endeavors. Prior to the development of many commercially-valuable electronic databases, such as digital libraries, ${ }^{95}$ there was little pressure on legislatures to enact sui generis database protection legislation. Since practical problems of database protection generally arise in the digital sphere, perhaps new legislative initiatives dealing with database protection should exclude the paper-based world and focus exclusively on digital databases. It is potentially much easier in practice to prevent unauthorized access to a physical library than to its digital counterpart.

Some commentators presume against paper by taking the view that database in today's market naturally refers to electronic, rather than physical, compilations of information. Carstens, for example, defines the term as follows:

93. 17 U.S.C. $§ 102(a)(1)$; see also id. § 101 (defining "literary work" as one that incorporates a work of narrative prose as a work "expressed in words, numbers, or other verbal or numerical symbols or other indicia, regardless of the nature of the material objects").

94. H.R. $354 \S 1401(2)$.

95. Such as Westlaw, LEXIS, and SSRN. 
A data base [sic] is simply a set of data stored and accessed by electronic means. No limit is put on the amount of data involved or on its arrangement. It may be a collection of full-text materials or a compilation of extracts of works. It may be a collection of material in the public domain, such as lists of names and addresses, prices, or reference numbers. Lastly, it may consist of the electronic publishing of a single but voluminous work, such as the encyclopaedia. The common thread is that a data base requires effort to compile and arrange. A computer program aids the compilation and retrieval process by allowing the user to create or manipulate the data base in a variety of ways. ${ }^{96}$

The original version of the E.U. Directive limited the scope of the Directive to collections of work stored and accessed by electronic means. ${ }^{97}$ However, some lawmakers argued that it would be difficult to limit legislation in such a way and that there may be no pragmatic reason for doing so. ${ }^{98}$ Why should paper-based databases and compilations not attract the same protections as electronic versions, particularly where there has been a substantial investment of time, money or effort in their creation? ${ }^{99}$

There are some important differences between the nature and value of electronic and paper-based databases. An electronic database may be more comprehensive than a paper-based version, easier to update frequently, and more able to offer targeted searches tailored to the needs of individual users.

Those favoring legal protection for paper-based databases would argue that despite these differences both electronic and paper-based databases may involve a substantial investment of time, money, and effort. The value of both types lie in the contents of the database and the ease with which they can be searched. Both types may have commercial value. Furthermore, advances in scanning and optical character recognition technologies render even paper-based databases vulnerable to cheap and efficient copying in both hard copy and electronic form. ${ }^{100}$

96. David W. Carstens, Legal Protection of Computer Software: Patents, Copyrights, and Trade Secrets, 20 J. CONTEMP. L. 13, 16 (1994) (emphases added).

97. IAN LLOYD, LEGAL ASPECTS OF THE INFORMATION SOCIETY 178 (2000).

98. Id.

99. Id.

100. U.S. COPYRIGHT OFF., REPORT ON LEGAL PROTECTION FOR DATABASES 41 (August 1997), available at http://www.copyright.gov/reports/dbase.html (last visited Aug. 3, 2003). This may or may not be a realistic concern, as it is still arguably more difficult and time consuming to optically scan and copy a large paper-based database than 
Nevertheless, most of the current problems in database protection involve electronic databases, which may or may not be electronic versions of databases that were originally paper-based. ${ }^{101}$ The leading Supreme Court authority limiting copyright protection in databases, Feist, ${ }^{102}$ involved a familiar form of paper-based database: a white pages telephone book. In Feist, the Court held that in order to qualify for copyright, a database must evidence some degree of originality in the selection or arrangement of its contents. ${ }^{103}$ The white pages telephone book failed to satisfy this threshold test.

However, although this case was decided in 1991, database protection did not become a significant issue in the United States until recently when major electronic database producers began developing significant business interests in the United States and elsewhere. ${ }^{104}$ This delay in addressing database protection may have occured because in the predominantly paper-based world of databases and compilations of over a decade ago it was easier to find enough creativity in the selection or arrangement of contents to establish copyright protection. The static, preformatted contents of paper-based databases tend to bear a unique imprimatur.

By contrast, in the electronic world, comprehensiveness, mutability, and functionality may add great commercial value to many large databases. ${ }^{105}$ This distinction may provide good reason for limiting the definition of database in any new laws to electronic compilations, as such compilations often indicate the line where copyright usually ceases to apply.

Though the Court in Feist noted that "the vast majority of compilations" would pass its test for copyrightability, ${ }^{106}$ the judges were

it is to copy an electronic database. It may be wise to monitor this issue and decide later whether database protection law should include paper-based databases.

101. The recent Australian case, Telstra v. Desktop Marketing, provides an example in which a compiler attempted to assert intellectual property rights (in this case, copyright) in electronic versions of white and yellow page telephone directories. Telstra Corp. v. Desktop Mktg. Sys. Pty Ltd. (2001) F.C.A. 612 (Austl.) (holding that Australian law offers copyright protection for phone books).

102. Feist Publ'ns v. Rural Tel. Serv. Co., 499 U.S. 340, 340 (1991).

103. Id. at $349-50$.

104. On commercial concerns of American database producers, see Jason R. Boyarski, The Heist of Feist: Protection for Collections of Information and the Possible Federalization of "Hot News", 21 CARDOZO L. REV. 871, 906-08 (1999). Among these is the enactment of the E.U. Directive and the fear that it would not give sufficient reciprocal protection to countries with inadequate database rights. Reichman \& Samuelson, supra note 9, at 96-97.

105. Brown, Bryan, \& Conley, supra note $40, \uparrow 46$.

106. Feist, 499 U.S. at 359. 
probably thinking in old, paper-based terms. In the digital age, the majority of databases probably fall outside the Feist test due to their electronic nature. ${ }^{107}$ Therein lies the argument for sui generis law that moves beyond the copyright model to protect other interests in compiled information.

\section{Private/Personal Databases}

Another danger with defining databases too broadly when drafting new laws is catching personal activity in the legislative net. Consider the position of a private individual who creates an electronic database for recording and searching her family tree. Would we expect or want such a database to be protected under a database protection law from unauthorized interference?

Copyright would protect a paper-based family tree as an expressive form. Copyright would also protect the software behind an electronic genealogy database. ${ }^{108}$ But would it serve any societal purpose to protect the contents of private information compilations when they are in electronic form? Because individuals are unlikely to commercialize their private databases, the commercial investment rationale for database protection falls away. If an unauthorized third party gains access to the information, the likely harm is not copying, rather interference with privacy. Thus for personal databases, protection should come from privacy law, ${ }^{109}$ not from laws protecting the value of commercial databases.

\section{Scientific, Technical, and Educational Databases}

Removing paper-based and purely personal compilations from the legal definition of a database should not interfere with the aims of legislation protecting the exploitation of commercial databases. More difficult questions, however, arise in relation to databases with significánt scientific, technical, or educational applications. Should we also remove these compilations from the definition of database so that no new law can commodify them as intellectual property and remove them from the public domain? Or should we include them in the definition along with permitted

107. This is because the value in such compilations is usually in the comprehensiveness of their contents and their non-selectivity. Austin, supra note 52, I 58; Brown, Bryan, \& Conley, supra note 40, ๆ 46.

108. Brown, Bryan, \& Conley, supra note $40, \uparrow 62$.

109. In the United States, privacy law remedies for misappropriation of such information may be somewhat lacking. See Litman, supra note 28 , at 1288 . However, if the information is stored in a private computer system, there may be remedies available under the common law of trespass. See eBay, Inc. v. Bidder's Edge, Inc., 100 F. Supp. 2d 1058 (N.D. Cal. 2000). 
use exceptions in order to protect certain scientific, technical, and educational uses of databases that may become commercialized?

A compromise between these two alternatives may best balance the interests of research and public knowledge against business goals. We can protect the public domain by omitting from the legislative definition of database compilations created purely for scientific, technical, or educational purposes with no underlying intent to commercialize them. Neither the producer nor the user of such a database could assert property rights in the compilation, thus ensuring that the contained information remains free.

By supporting open source licensing provisions, the law could even encourage contractual provisions prohibiting the subsequent commercialization of such database contents. ${ }^{110}$ This may be particularly appropriate for databases initially created using government funding, where there are strong policy arguments for leaving such databases in the public domain and prohibiting their subsequent commercialization by parties who were not involved in their creation.

In contrast, information compilations created with multiple purposescommercial along with scientific or educational uses-merit protection under the rationale I propose for sui generis database law. Thus, these compilations should fall under any legislation's definition of database. Once the definition includes such databases, some of the more significant risks to science and education posed by the over-commodification of these databases can be lessened by including exceptions to the prohibited uses. ${ }^{111}$ Yet, limiting the definition initially to commercial databases will minimize the need for parties to rely on these exceptions.

Finally, database law should include compulsory licensing provisions that allow those working in science, technology, and education to access and use databases comiled by sole providers of important scientific, technical, and educational material. These difficult questions must be thoroughly debated prior to the enactment of any new legislation. ${ }^{112}$

110. These are provisions that restrict future propertization of information subject to the license. For a detailed discussion of open source licensing, see Dennis M Kennedy, $A$ Primer on Open Source Licensing Legal Issues: Copyright, Copyleft and Copyfuture, 20 ST. LOUIS U. PUB. L. REV. 345, 347-48 (2001).

111. Government oversight might be useful in policing this; for example, under some kind of dispute resolution mechanism.

112. Hughes, supra note 8 , at $48-51$; Reichman \& Uhlir, supra note 29 , at $799-821$ (discussing potential effects of sui generis database protection on scientific and technology communities). 


\section{A Proposed New Database Definition}

Given these issues, how should we draft a targeted, robust definition of the databases we wish a new law to protect? One could start with the E.U. Directive approach (involving a relatively generic description of a database), but then except, as a matter of public policy, items that should not be protected under the law.

To achieve the purpose of serving the commercial needs of database producers, the generic part of the definition should include only databases produced with the intention of commercially exploiting them in one or more identified markets. ${ }^{113}$ The definition could, for example, begin by extending to all collections of information, facts, or works ${ }^{114}$ developed at least partly for commercial exploitation in identified markets. The definition could then exclude: (a) paper-based databases, (b) educational or teaching materials, (c) scientific and technical materials not developed with the intention of commercial exploitation, and (d) compilations developed for private or personal use with no commercial intent.

This approach is similar to the European approach to defining patentable subject matter. The European definition of patentable subjectmatter begins broadly ${ }^{115}$ and then excludes a list of subject matter not eligible for patent. ${ }^{116}$ These exclusions cover subject matter adequately protected by other intellectual property laws ${ }^{117}$ and subject matter that should not be protected as a matter of public policy. ${ }^{118}$

Defining databases as compilations created for commercial exploitation in particular markets would link the definition directly to the commercial aims of the legislation. As examined in Part IV, applying such a definition in practice may require registration of the database for use in identified markets and government investigation of a business plan showing how the database will be exploited in these markets. Trademark law provides a basis for drafting such provisions.

113. The following discussion takes up the question of how a bona fide intention to commercialize a database in one or more relevant markets might be assessed for the purposes of the legislation and does suggest some government oversight as with trademark and, to some extent, patent law.

114. Such terms could be defined in ways suggested from the E.U. Directive, the Antipiracy Bill, and the Consumer and Investor Access Bill.

115. See, e.g., Patents Act, 1977, § 1(1) (Eng.) (transposing the requirements of the European Patent Convention into domestic English law).

116. Id. $\S \S 1(2) \& 1(3)$.

117. See, e.g., id. $\S 1(2)(b)$.

118. See, e.g., id. $\S \S 1(2)(\mathrm{a}), 1(2)(\mathrm{c}), 1(2)(\mathrm{d}), 1(3)$. 
A discrete definition will lessen confusion similar to that found in copyright about the proper scope of the fair use exceptions. ${ }^{119}$ In particular, it will lessen confusion over whether fair use is a constitutional right or rather a tolerated convenience. ${ }^{120}$ By using the definition of database to depart from the copyright model, a new sui generis database law can succeed where a copyright-inspired model would fail in protecting the elements of a database that modern commercial database producers seek to protect. ${ }^{12}$ This is because limiting the definition of database lessens the need to rely on fair use exceptions to database rights.

Thus, following the European patent law model may be the best way to define databases: (1) strictly limit the concept of a database to those developed for commercial exploitation, similar to registered trademark law; (2) carve out of the definition those elements that are adequately protected by other intellectual property laws or those whose inclusion would be against public policy; (3) amend the list of "carve outs" if the list fails to meet the needs society and commerce. Drafters of an American or an international database protection law should carefully consider this approach.

\section{Commercial Exploitation of Databases}

Accepting that developing an appropriate initial definition of database is essential for effective database protection laws in the digital age, we must then identify the uses a database creator may want to make of the database and the sort of legal protections these uses may require. This is essential to framing effective and appropriate legislative prohibitions on database use.

Producers must be able to effectively commercialize their information product and clearly set down the contractual rights and obligations of people granted access to the database. Additionally, they must be able to prevent unauthorized access to the database by third parties who have not contracted with them. Legislatures should support any contractual or technological measures used by database producers to achieve these ends as long as those measures do not encroach inappropriately upon any legitimate public interest in free access to information and ideas.

119. DAVID, supra note 69, at 5-6; LEAFFER, supra note 81 , at 428 .

120. Nimmer, supra note 33 , at 714-15.

121. There is an associated risk here that any law to protect databases that is too closely modeled on copyright runs the risk of being struck down as unconstitutional. See, e.g., Malla Pollack, The Right to Know? Delimiting Database Protection at the Juncture of the Commerce Clause, the Intellectual Property Clause, and the First Amendment, 17 CARDOZO ARTS \& ENT. L.J. 47 (1999); U.S. COPYRIGHT OFF., supra note 100, at xviii. 
Professor Conley summarizes the objectives of a commercial databaseproducer as follows:

The objectives of a rationally self-interested database owner will be: (1) to permit authorized persons to use the database fully; (2) to prevent unauthorized persons from using it; and (3) to prevent competitors from copying it in order to create a competitive product. A database owner will judge the adequacy of any form of legal protection according to its capacity to advance these three interrelated objectives. ${ }^{122}$

It may be difficult to produce evidence of a bona fide intention to commercially exploit a database. However, a law confined to protecting only the commercial aspects of databases, rather than protecting compilations of information per se, will have the greatest chance of gaining public acceptance and operating effectively.

Commercial exploitation need not be limited to commercial licensing but may include the database compiler's own uses in commerce. For example, a retail company that collects its customers' spending profiles in a database for use in targeted marketing might be regarded as performing a commercial use.

Contract law may be an appropriate means to deal with some of the above requirements. However, the creation of proprietary rights in databases through intellectual property law is also important here but has proven to be more problematic than contracting per se. It is important to legally define the actual proprietary or quasi-proprietary rights of commercial parties so that they may contract effectively with respect to those rights. ${ }^{123}$

Intellectual property rights are also important because contract law cannot always deal effectively with the prevention of unauthorized third party access to database contents. A third party lacking permission to access a database or to use its contents may not be in a contractual relationship with the database maker. Furthermore, even in the situation where a contract exists, the wrongdoer may be acting outside the scope of the contract terms.

When a contracting party uses database content outside the scope of its contract, contractual remedies will be available if the wrongdoer can be identified and made subject to the jurisdiction of a court or other dispute-

122. Brown, Bryan, \& Conley, supra note $40, \uparrow 35$.

123. As noted by Professor Litman, "The raison d'etre of property is alienability .... Property law gives owners control over an item and the ability to sell or license it." See Litman, supra note 28, at 1295. 
resolution forum. However, proprietary remedies may prove to be more meaningful and useful in such circumstances. Certainly, proprietary remedies will be the only useful legal avenue where unauthorized third party access to a database occurs in the absence of a contractual relationship between the parties. For this reason, the discussion now turns to the creation of proprietary or quasi-proprietary rights and remedies in databases.

It should be noted that in the modern technological world, legal protection cannot, and should not, be the only avenue of protection for the contents of electronic databases. Technological protection measuressuch as encryption devices, watermarks, and time-limited software mechanisms to prevent unauthorized ongoing use of database contentsshould also be employed by database makers to the extent possible and practicable. ${ }^{124}$ In many cases, a legal remedy will be less useful than an effective technological measure. The law can only assist efforts taken by parties to protect their information. The law cannot solve all access and use problems, particularly when wrongdoers operate across national borders and evade the laws or jurisdiction of the database maker. ${ }^{125}$

However, there are also practical limitations to pure reliance on technological measures. As noted in a 1999 National Research Council report, "it is almost certain that every technological security method will eventually be able to be countered through the use of other technological advances." ${ }^{\text {126 }}$ Thus, law and technology need to work together to provide adequate protection.

Any new database protection law should support contract and technology protection measures as long as they protect valid proprietary rights in information compilations without interfering unnecessarily with competing public interests. However, when contract or technology protection measures go too far in monopolizing information to the detriment of the public interest, the law should strike down the measure as an unjustified incursion into the public domain. ${ }^{127}$

124. Peter N. Grabosky \& Russell Smith, Crime in the Digital Age: CONTROLLING TELECOMMUNICATIONS AND CYBERSPACE Illegalities 112-13 (1998); NAT'L RESEARCH COUNCIL, supra note 55, ch. 3.

125. This has been a problem of copyright protection in the digital age. Even new legislative measures such as the DMCA encounter difficulty in the international arena. Lipton, Comparative Survey, supra note 33, at 365-69.

126. NAT'L RESEARCH COUNCIL, supra note 55 , ch. 3.

127. Cohen, supra note 65 , at 608-09 (on justifications for striking down contract and technological protection measures in the public interest). 
Assuming that an appropriate database protection law will confine itself to supporting the reasonable commercial exploitation of databases, the key requirements of database producers may well be those identified by Professor Conley, including the right to: (a) permit authorized persons to utilize database contents; (b) prevent unauthorized persons from accessing or using database contents; and (c) prevent competitors from copying or distributing database contents without authorization. This approach to delimiting relevant rights might be acceptable if the exact boundaries of these rights are clearly defined. In particular, some form of statutory time limit on the exercise of these rights seems important, as does clearly limiting the rights to appropriate commercial uses that do not encroach too significantly into the public domain of information and ideas.

The time limit imposed on the exercise of such rights might be calculated in several ways: (1) based on the amount of time, cost, or effort invested in creating the relevant database; (2) by giving the database creator a reasonable "commercial head start" over its competitors as a reward for its efforts; or (3) on some other basis such as an arbitrary number of years. ${ }^{128}$

\section{CRITIQUE OF EXISTING LAWS}

Whether or not a new database law ever incorporates the rights listed above, it seems clear that Professor Conley has correctly identified these rights as the aims of a "rationally self-interested database owner." ${ }^{.29}$ This part of the discussion identifies how current intellectual property laws fail to achieve these aims. It then turns to suggestions for effective database law reform at both the domestic and international levels.

Since 1996, Congress has introduced a number of bills to create some form of database protection system for the United States. ${ }^{130}$ However, Congress has yet to reach agreement on the key features of such a new law, particularly the nature and duration of the rights that must be created in databases in order to satisfy the reasonable commercial requirements of database makers. Furthermore, Congress has not agreed on the exceptions

128. Wesley L. Austin, A Thoughtful and Practical Analysis of Database Protection Under Copyright Law, and a Critique of Sui Generis Protection, 3 J. TECH. L. \& POL'Y 3, I 86 (1997) (on file with the author), available at http://journal.law.ufl.edu/ techlaw/31/austin.html (last visited Aug. 9, 2003); Wolken, supra note 67, at 1299.

129. Brown, Bryan, \& Conley, supra note 40, I 35.

130. For a useful summary of legislative activity in the United States to date, see Brown, Bryan, \& Conley, supra note 40, ๆๆ 87-91, and Mark Davison, Proposed U.S. Database Legislation: A Comparison with the U.K. Database Regulations, 21 EuR. INTELLECTUAL PROP. REV. 279 (1999). 
that need to be carved out of those rights to protect legitimate public interests. The approaches to drafting these laws shows the influence of the copyright-based model on commentators and legislators. New laws will not likely be drafted optimally until the debate stops revolving around the perceived failure of copyright to protect databases and begins to focus on balancing the commercial needs of database creators against those of the public at large.

Certainly, any new database protection law must take account of applicable copyright concerns. However, those concerns should be secondary to how the new law itself is modeled. The primary concern should be the underlying conception of a "database" and determining what that term should cover, with an eye towards meeting the real commercial needs of database producers. Given the nature of the information products under consideration and the significant risk of over-commodifying the public domain if regulatory matters are left completely in the hands of the marketplace, the debate should also recognize the need for some level of government monitoring.

The various House bills introduced since 1996 include the following:

1) Database Investment and Intellectual Property Antipiracy Bill of 1996 which closely followed the strongly "proprietary" E.U. model but established a longer (twenty-five-year) period of protection and gave broader rights of exclusion to database makers. ${ }^{131}$

2) Collections of Information Antipiracy Bill of 1997 which also broadly followed the E.U. model but imposed no time limit on protection. ${ }^{132}$ This bill allowed some "permitted acts" in relation to a collection of information, but these were regarded by many as insufficient. Originally, these provisions were to be part of what was to become the DMCA, but they were deleted before both houses passed the DMCA in 1998.

3) Collections of Information Antipiracy Bill of 1999 which broadly followed the previous bills but created a new fair use exception to infringement and -in the version as originally introduced-limited the protection period to fifteen years. ${ }^{133}$

131. H.R. 3531, 104th Cong. (1996).

132. H.R. 2652, 105th Cong. (1996).

133. H.R. 354, 106th Cong. (1999). 
4) Consumer and Investor Access to Information Bill of $1999,{ }^{134}$ which prohibited the duplication and commercial sale of a database in competition with the original database but did not expressly create proprietary rights in a database ${ }^{135}$ and did maintain a significant list of permitted acts ${ }^{136}$ in relation to databases.

None of these models has found its way into American law, partly because of disagreements as to how such a law should be drafted and partly because of opposition to all of these approaches from the scientific and technological communities in the United States. ${ }^{137}$ These approaches have missed the main issues in this area on which legislators should be focused. All of these bills define databases very broadly, creating potentially far-reaching rights in databases, ${ }^{138}$ tempered by vague fair use style exceptions to those rights to balance public and private interests.

A more effective model for database law might clarify points of fundamental importance to the database debate. For example, it is fundamentally important to precisely identify which databases should be regulated and on what basis. It is also crucial that the government effectively monitor the exploitation of database rights in order to prevent the unfettered promotion of commercial activity at the expense of the public interest.

Before considering how these more fundamental issues could be resolved in a model for a new database law, it is necessary to consider the ways in which existing laws fail to strike an appropriate balance between the reasonable commercial needs of database producers and fears regarding the over-commodification of information in the digital age. In so doing, we should keep in mind the aims of database producers in restricting access to databases and preventing unfair commercial competition. Any new database legislation needs to be strictly limited to

134. H.R. 1858, 106th Cong. (1999).

135. However, arguably it does so at least by implication. See discussion infra Part III.C.2.

136. These look somewhat like the fair use exceptions from copyright law. See following discussion Part III.A.

137. Hughes, supra note 8 , at 52-55 (discussing the political and market forces behind the debates for database protection legislation in the United States and in other jurisdictions); Reichman \& Uhlir, supra note 29, at 823-28.

138. The protected rights under the Consumer and Investor Access to Information Bill are much more limited than those under the various iterations of the Collections of Information Antipiracy Bill. However, I would still argue that the Consumer and Investor Access to Information Bill is overly broad in its definition of database and overly vague in terms of its fair use exceptions to be particularly effective. 
meeting these ends without interfering with the broader "intellectual property bargain" in society. Again, we are confronted with the complex problem of balancing private rights against public interests in information. This may be an area where government oversight of relevant laws might be useful in striking an appropriate balance.

\section{A. Copyright}

\section{Copyrighting Databases: The Feist Decision}

It is logical to commence this discussion with an examination of copyright law as a vehicle for protecting valuable databases against unauthorized access or use. Copyright was originally regarded as one of the most obvious methods for protecting at least certain types of databases. In most jurisdictions, including the United States and the United Kingdom, copyright law protects a "compilation" or "database" as a "literary work" provided that it meets the statutory requirements for such protection. In England, section $3 \mathrm{~A}(2)$ of the CDPA provides that a database will be protected in this way if "by reason of the selection or arrangement of the contents of the database the database constitutes the author's own intellectual creation." 139

In the United States, various provisions of the Copyright Act as interpreted by the courts also similarly protect databases. The copyright subsists in "original works of authorship fixed in any tangible medium of expression." 140 Section 103(a) of the Act acknowledges that copyright protection extends to "compilations" and "derivative works," but this is tempered by section 103(b) which provides that copyright protection extends only to the material contributed by the author of such work and not to pre-existing material employed in the work.

Under United States copyright law, "compilation" is defined in section 101 as:

[A] work formed by the collection and assembling of preexisting materials or of data that are selected, coordinated, or arranged in such a way that the resulting work as a whole constitutes an original work of authorship. The term "compilation" includes collective works.

For the purposes of the definition of "compilation," the term "collective work" is further defined in $\S 101$ as:

139. CDPA, $\S 3 \mathrm{~A}(2)$. This closely follows the wording of the E.U. Directive, Article $3(1)$.

140. 17 U.S.C. $\S 102(a)$ (2000). 
[A] work, such as a periodical issue, anthology, or encyclopedia, in which a number of contributions, constituting separate and independent works in themselves, are assembled into a collective whole.

Although the terminology and underlying concepts differ slightly, these definitions are clearly related to the concept of a database as defined in the CDPA in England. In particular, there is no direct guidance in the U.S.C. about whether the exertion of time, money, or effort in compiling a database would suffice to trigger copyright protection or whether U.S. copyright law requires a greater degree of originality or creativity. These questions have always been left to the courts in the United States. ${ }^{141}$

The authoritative case on this point is the 1991 Supreme Court decision in Feist in which the Court rejected the previously established "sweat of the brow" doctrine as applied to compilations and databases. ${ }^{142}$ The "sweat of the brow" doctrine had held that if substantial work had been put into creating a database, this work would satisfy the originality requirements of copyright law. ${ }^{143}$ The Court in Feist held that the threshold test for acquiring copyright protection in a database is whether there is some originality present in the selection or arrangement of the contents of the database. ${ }^{144}$ Evidence of sufficient exertions in creating the database no longer satisfied the originality requirement.

Thus, the plaintiffs in Feist could not assert copyright protection for a white pages telephone directory because the Court held that originality was not present in the selection, arrangement, or organization of database content:

Rural's selection of listings could not be more obvious; it publishes the most basic information-name, town, and telephone number-about each person who applies to it for telephone service. This is "selection" of a sort, but it lacks the modicum of creativity necessary to transform mere selection into copyrightable expression. Rural expended sufficient effort to

141. These questions had also been left to the courts in England prior to the transposition of the E.U. Database Directive into national law there in 1997. The definitions of database in the CDPA in England transposed into domestic legislation the judicial tests that have been used in the United States to define the standard of creativity required for copyright protection of a database which had also been adopted in the E.U. Directive. See E.U. Directive, supra note 27, art. 3(1).

142. Feist Publ'ns v. Rural Tel. Serv. Co., 499 U.S. 340, 363-64 (1991).

143. Id. at $352-53$.

144. Id. at 348 . 
make the white pages directory useful, but insufficient creativity to make it original. ${ }^{145}$

In explaining the scope of the originality requirement as applied to databases and compilations, Justice O'Connor noted:

Originality requires only that the author make the selection or arrangement independently (i.e., without copying that selection or arrangement from another work), and that it display some minimal level of creativity. Presumably, the vast majority of compilations will pass this test, but not all will. There remains a narrow category of works in which the creative spark is utterly lacking or so trivial as to be virtually non-existent .... Such works are incapable of sustaining a valid copyright. ${ }^{146}$

Although the Feist test is the current approach for ascertaining whether copyright can be asserted in a database in the United States, it has come under criticism both within the United States and elsewhere. ${ }^{147}$ It has been suggested that one of the fundamental problems with the Feist decision is that it provides no guidance as to what types of databases will attract copyright protection in the United States. By setting the standard against a white pages telephone directory-arguably one of the least creative compilations possible - the Supreme Court does not give future courts and commercial entities sufficient guidance as to where the line should be drawn between copyrightable and non-copyrightable databases. ${ }^{148}$

The Feist decision also fails to recognize that the value of many computerized databases is in their comprehensiveness. The more information databases contain and the less "selection" they evidence, the more commercially valuable they are likely to become. Such comprehensiveness often requires database makers to exercise minimal selectivity in creating the compilation. ${ }^{149}$ This leads to the paradox that the more commercially valuable the database is, the less likely it is to achieve copyright protection. ${ }^{150} \mathrm{~A}$ more selective database is arguably less valuable yet more likely to achieve greater intellectual property protection through copyright. ${ }^{151}$

145. Id. at $362-63$.

146. Id. at 358-59.

147. See discussion infra Part III.A.2.

148. Brown, Bryan, \& Conley, supra note 40, ๆ 46.

149. Id. \61.

150. Id.; see also Austin, supra note 52, \58.

151. Wolken, supra note 67, at 1278. 
Jeffrey Wolken notes that the same problems arise in applying the original "arrangement" criterion to electronic databases to determine copyrightability:

[I]mposing a definite, physical arrangement on the information contained in a database would severely decrease the database's utility. Even if database producers wanted to gain copyright protection by providing a definite physical arrangement when saving their information, it is not practical for them to do so. In addition to the limitations imposed by the physical process of randomly saving computerized information, any formal arrangement of information would detract from the usefulness of a database. It is the ability of users to search an unrestricted database for the information they want that makes the database valuable. After a search, a user can create for himself the best presentation of the information by imposing his own arrangement on the search results. Generally, the utility of a database is inversely related to the degree of arrangement originally found in the database. More structure equals less utility. Therefore, using "arrangement" as a protectable element of a computerized database is both unfeasible and impractical. ${ }^{152}$

Thus, copyright law in the wake of the Feist decision is arguably too thin, failing to protect many databases that are the product of substantial investments of time, effort, and money, but show little creativity in selection and arrangement. ${ }^{153}$

Attempts to protect the value of such databases through other legal measures are also problematic. For example, trade secret law has little application to databases because the way in which a database's information is commercialized often makes it difficult to keep the information secret. ${ }^{154}$ Furthermore, a database that is not sufficiently original to attract copyright protection will almost certainly not satisfy patent law's novelty and non§obviousness requirements. ${ }^{155}$

Contract protection is also problematic. First, the wrongdoer may not be in a contractual relationship with the database maker. ${ }^{156}$ Second, even if there is a contractual relationship, the database maker may be unable to obtain assent to restrictive contractual clauses limiting the permitted uses

152. Id. at 1277-78.

153. Brown, Bryan, \& Conley, supra note $40,970$.

154. MANN \& WINN, supra note 61 , at 377.

155. 35 U.S.C. $\S \S 102-103$ (1994).

156. It may be that concepts of implied contract may be useful here in some situations. 
of database contents. Obtaining such assent may also be inconsistent with the database maker's business objectives. ${ }^{157}$ Third, some still the question the validity and enforceability of clickwrap licenses relating to contractually permitted uses of information ${ }^{158}$ despite some judicial ${ }^{159}$ and legislative ${ }^{160}$ support for such terms. Fourth, jurisdictional problems may prevent the enforcement of such terms, particularly where the alleged wrongdoer is located interstate or overseas from a database producer. ${ }^{161}$ Finally, in online commerce, a complainant database producer may not be able to find or identify a contracting party who has breached contract terms-an issue obviously not unique to contract law.

The Feist copyright protection standard fails to meet a database producer's key objectives as identified by Professor Conley. The standard fails to allow any rights in a database that lacks sufficient originality in the selection or arrangement of its contents. Therefore, the Feist standard will exclude copyright protection for many valuable commercial databases. ${ }^{162}$

2. International Criticism of the Feist Decision: Telstra v. Desktop Marketing Systems

The Feist decision has also attracted critics outside the United States. In the recent Australian Federal Court case of Telstra Corp. v. Desktop Marketing Systems ${ }^{163}$, Judge Finkelstein criticized the U.S. position. In Telestra, Judge Finkelstein was ruling on a factual situation very similar to Feist, except the Telstra case involved electronic versions of what were paper-based telephone directories in Feist. ${ }^{164}$

In Telstra, Desktop Marketing Systems reused without permission significant amounts of information contained in Telstra's white pages and yellow pages directories. Judge Finkelstein held that Telstra could assert copyright in both its white and yellow page directories. ${ }^{165}$ The selection

157. Brown, Bryan, \& Conley, supra note 40, ๆ $39,70$.

158. Madison, supra note 38 at $1117-19$.

159. ProCD, Inc. v. Zeidenberg, 86 F.3d 1447, 1447 (7th Cir. 1996).

160. For example, UCITA has been enacted to date in several States including Maryland and Virginia. See in particular U.C.I.T.A. § 112 (2001).

161. It should be noted that with information commerce in the digital age, this problem is not limited to contract law.

162. RADIN, supra note 49 , at 763.

163. (2001) F.C.A. 612 (Austl.).

164. This fact may lend weight to the point that it is really electronic commerce that requires the protection of any new database laws, and that there may be good reasons to exclude paper-based databases from their reach. See id.

165. The Australian Federal Court of Appeal upheld Judge Finkelstein's first instance decision in the case. Desktop Mktg. Sys. v. Telstra Corp. (2002) F.C.A.F.C. 112 (Austl.). Moreover, because the High Court of Australia has recently refused leave to appeal the 
and arrangement of the contents showed sufficient originality to attract copyright protection.

In considering Desktop's arguments citing the Feist decision, Judge Finkelstein suggested that Justice O'Connor in Feist may have been incorrect when she said that limiting copyright in compilations to those where there has been an exercise of judgment will not affect many publications. ${ }^{166}$ The Feist decision's outcome is that many obvious methods of grouping or listing data-for example, alphabetically, chronologically, or sequentially-will be denied originality even though the obviousness of the selection and arrangement may give the database its value. ${ }^{167}$ Judge Finkelstein suggested that the Feist court made a mistake when it assumed that its ruling would be limited only to those circumstances in which originality would not be found in a database. ${ }^{168}$

Judge Finkelstein also noted that Feist has caused much confusion in subsequent cases in the United States dealing with various yellow page telephone directories. ${ }^{169}$ This implied that it would be imprudent for Australia to embrace law that could cause similar problems in future cases. Judge Finkelstein then weighed the practical advantages and disadvantages of following a similar rule in Australia and concluded that:

There are policy reasons both for and against the result in Feist ... . On the one hand, the ability to prevent others from appropriating information in a compilation of facts will severely limit the ability of later authors to build upon earlier works. This may impair progress in both the sciences and the arts .... On the other hand, there are those who argue that the abandonment of the "sweat of the brow" theory has threatened the progress of information. The argument is that the collection of factual

decision, the Full Court Decision will stand as the current law in Australia. Result of Applications for Special Leave to Appeal, High Court of Australia (June 20, 2003), at http://www.hcourt.gov.au/registry/slresults/20-06-03M.htm

166. Feist Publ'ns v. Rural Tel. Serv. Co., 499 U.S. 340, 358-59 (1991).

167. Telstra, F.C.A. 612 at $\uparrow 74$.

168. Feist, 499 U.S. at 358-59. In fairness, we must remember that Feist was decided in the early $1990 \mathrm{~s}$, prior to the rise of electronic databases as a major worldwide commercial industry.

169. Telstra, F.C.A. 612 at ๆ $76-79$. Judge Finkelstein also discusses relevant Canadian case law in a similar vein to Feist. See, e.g., Tele-Direct Inc. v. Am. Bus. Info. Inc., [1997] 154 D.L.R. 4th 328 (Fed. Ct.) (Can.) (holding that copyright did not subsist in a yellow pages directory because the publisher had exercised only a minimal degree of skill or judgment in the overall arrangement of the publication which was insufficient to support a claim for originality). The fact that there was industrious collection of the information was not regarded as relevant. $I d$. 
material is essential to the economy. Databases provide a wealth of information to business people, professionals, scientists and consumers. If copyright protection is not given, the investment of the time and money that is required to produce these compilations will not be forthcoming. ${ }^{170}$

The answer to the problems listed by Finkelstein may be to extend copyright protection to databases where a substantial investment has been made in their creation, but there may be a better alternative. England, for example, has recently replaced the "sweat of the brow" theory of copyright protection for compilations and databases with a sui generis database right for databases whose selection and arrangement do not meet originality requirements of copyright. Of course, copyright is still available in England for those databases that meet the originality criteria. ${ }^{171}$ These developments are largely the result of the requirement that English law comply with the E.U. Directive of 1996, discussed in the next section.

The English and E.U. laws create overly broad new sui generis intellectual property rights in databases that are too closely based on copyright concepts and go well beyond the reasonable needs of commercial database producers. ${ }^{172}$ However, these laws do show that many parts of the world do not regard copyright protection as a sufficient or appropriate way to protect the commercial value of electronic databases. The drafting of a number of database protection bills within the United States ${ }^{173}$ shows similar concerns.

Even those who criticize both the E.U. and U.S. approaches are not unsympathetic to the conundrum described by Judge Finkelstein. In the introduction to their seminal article on database protection in the United States, Professors Reichman and Samuelson stated:

The Authors of this Article are not unsympathetic to many of the goals that the sui generis database regimes are meant to achieve. We have elsewhere argued that the traditional intellectual property models, as supplemented by trade secret laws, often fail to afford those who produce today's most commercially valuable information goods enough lead time to recoup their investments. The risk of market failure inherent in this state of chronic under-

170. Telstra, F.C.A. 612 at $\uparrow 83$.

171. CDPA, supra note $80, \S 3 \mathrm{~A}$.

172. Reichman \& Samuelson, supra note 9 , at $84-95$.

173. See the discussion infra Part III for details of the various bills drafted in the United States to date. 
protection tends to keep the production of information goods at suboptimal levels. ${ }^{174}$

Although ultimately rejecting the suggestion that the United States should adopt a database right like that now available in the European Union, Professors Reichman and Samuelson suggest that there should be some additional form of protection for databases based on a different model. ${ }^{175}$

\section{Limitations of Copyright Law in the Database Context}

Having surveyed the different approaches to copyrighting databases in various jurisdictions, copyright clearly is not the most appropriate way to protect the commercial value of many databases, notably electronic databases. Even absent the concerns raised about copyright law's inability to protect unoriginal databases, the policies underlying copyright law are not appropriate for commercial database protection.

In jurisdictions and circumstances where copyright protection is available for databases, the copyright protection will arguably be greater than necessary. ${ }^{176}$ Even though such protection might provide incentives encouraging the production of databases, the ensuing protection may stifle development of products that compete with those databases. Development might be stifled even for products that would not directly compete in the same market but which used existing database content in a different field. ${ }^{177}$

Although created as private property rights by statute, copyrights in most jurisdictions are largely exploited and enforced under market control. As argued previously and taken up further in the following discussion, the creation and exploitation of private property rights in databases may require a higher degree of government oversight than currently exists under copyright law.

Even if a "sweat of the brow" doctrine for copyright protection of databases were accepted across many jurisdictions, ${ }^{178}$ is this really what copyright law was designed to protect? Although there is a significant history of "sweat of the brow" cases being upheld in jurisdictions such as

174. Reichman \& Samuelson, supra note 9, at 55.

175. Id. at 137-63.

176. This is even more so when the "sweat of the brow" doctrine is accepted as the basis for copyright protection (as it is in some jurisdictions like Australia), and a broader range of databases are potentially protected as copyrightable works.

177. Reichman \& Samuelson, supra note 9, at 125-26.

178. This seems unlikely to happen in practice, particularly in jurisdictions such as the United States. 
the United States (pre-Feist), the United Kingdom (prior to the E.U. Directive) and Australia, this history may have been underscored by policy concerns on the part of judges that defendants should not "reap where they have not sown," and that copyright should come into play to prevent such appropriations in the absence of any other effective form of intellectual property protection for databases and compilations. Thus, it may be preferable to develop new rights tailored to commercializing valuable databases.

Copyright law is about expression, not about ideas. ${ }^{179}$ Copyright in a database should not extend protection to the database's valuable elements - the facts and information contained therein. ${ }^{180}$ Yet, the indirect effect of the "sweat of the brow" doctrine may have been to extend copyright in this direction. ${ }^{181}$ This is another argument for removing the "sweat of the brow" doctrine from copyright law, as Feist effectively did in the United States.

Copyright law was created and structured to protect artistic rights, ${ }^{182}$ not commercial rights, even though it has been used to protect commercial activities. ${ }^{183}$ Rather than pulling copyright law further towards commercial and non-artistic objectives, legislatures should create a new law with clearly commercial aims and structures that deals with the commercial exploitation of databases. ${ }^{184}$

Because a copyright in a database or compilation protects only the selection and arrangement of the contents of the database, ${ }^{185}$ a producer of a second database could avoid copyright infringement by copying only facts from a copyrighted database rather than expression of these facts. For

179. BouCHOUX, supra note 74 , at 146.

180. Austin, supra note $52, \uparrow 1$.

181. See Wolken, supra note 67, at 1273-75.

182. BouchouX, supra note 74 , at 133-38. However, it should be noted for completeness that much of early English copyright law was based on commercial imperatives related to the publishing industry, and that the United States clearly followed this tradition. See W.R. Cornish, Intellectual Property: PATENTS, Copyright, TRADE MARKS AND ALLIED RighTS, ch. 9 (4th ed. 1999).

183. An obvious example is the reliance by movie studios on copyright, and on the recently enacted provisions of the DMCA, to protect property rights in movies released on DVD for public sale. This was the basis of the litigation in Reimerdes. Universal City Studios Inc. v. Reimerdes, 111 F. Supp. 2d 294, 344-45 (S.D.N.Y. 2000).

184. As noted above, the new law could be modeled more directly on concepts derived from patent and trademark laws to the extent that they focus more clearly on creating commercial intellectual property rights, rather than artistic rights that are based on the prevention of copying.

185. CDPA, supra note $80, \S 3 \mathrm{~A}(2)$; Feist Publ'ns v. Rural Tel. Serv. Co., 499 U.S. 340,348 (1991). 
examples, a second producer could rearrange the database contents into a different format, which is inexpensive and easy to achieve with digital technologies. ${ }^{186}$

Copyright law will continue to protect certain aspects of some databases in many jurisdictions, including the United States, the European Union, and Australia. Yet there is no international consensus that copyright is the most appropriate way to protect a database's commercial value. In fact, the consensus is that copyright is clearly an inappropriate vehicle for many of the reasons described above. For example, copyright is clearly inappropriate for broad comprehensive electronic databases whose value lies in their coverage and ease of searching, rather than their originality in selection or arrangement of information. For this reason, copyright law is not a long-term solution to the commercial needs of modern electronic database producers.

\section{B. Trade Secrecy}

\section{Basis of Trade Secret Law}

Trade secret protection has a much more limited application to databases than copyright law. ${ }^{187}$ In the United States, trade secret law is a body of both state and, more recently, federal law ${ }^{188}$ that protects the value

186. Wolken, supra note 67 , at $1279-80$.

187. It should be noted that trade secret law is the only aspect of state law from the United States considered in this discussion. This is because it is the most relevant part of state law to the discussion of the protection of information contained in a commercially valuable database. For completeness, it should be noted that there are some other parts of state law that may have some relevance in the database context, although they are even more vague and arguably of more questionable application in this context than trade secret law. They have thus been omitted from this discussion. The most notable such area of state law, potentially relevant to protecting facts and ideas that are not otherwise protected by patent or trade secret law is the somewhat vague and non-uniform "misappropriation" doctrine based on the Supreme Court case of International News Service v. Associated Press, 248 U.S. 215 (1918). Although no longer part of the federal common law, the doctrine has arguably survived in state law in at least some states and may apply to situations where a person has invested substantially in the creation of a valuable intangible item relating to information that is not otherwise protected by patent or trade secrecy, and where a second person has appropriated his or her idea as a free rider at little cost, thereby injuring the original developer. State courts will sometimes grant injunctions or award damages in such circumstances to counter the effect of freeriding on the original developer of the intangible product. This doctrine has been severely criticized and is very rarely raised in litigation in practice. The doctrine is arguably preempted by federal patent and copyright law, which is why no space has been devoted to it in the main text. See LEAFFER, supra note 81, at 41-43; Boyarski, supra note 104, at 871; Brown, Bryan, \& Conley, supra note 40, $1 \uparrow$ 39-40.

188. Economic Espionage Act, 18 U.S.C. $\S 90$ (1996). 
of information kept out of the public domain through secrecy and obligations of confidence. ${ }^{189}$ Comparable doctrines have developed in other countries. ${ }^{190}$

The ability of trade secrecy to protect valuable commercial information that is not particularly novel or creative is an advantage over other intellectual property law. Specifically, when compared to patent law, trade secrecy (a) protects a potentially broader array of non-novel information, such as customer lists and marketing plans; ${ }^{191}$ and (b) does not require patent law's high standards of inventiveness. ${ }^{192}$ Because of these advantages, some businesses choose to rely on trade secret protection rather than patent protection. This is especially true where the information in question is not novel, inventive, or the information's value does not justify the time and expense of seeking a patent. ${ }^{193}$

In fact, even where an invention would be patentable, many businesses choose to keep it secret because they can then obtain a much longer period of protection than a patent's twenty-year term. ${ }^{194}$ For example, Professor Leaffer notes that for business processes such as the formula for CocaCola trade secrecy is more attractive than a patent. ${ }^{195}$ Trade secrecy allows a few people to practice the invention in secret, particularly where reverse engineering of the invention is difficult. ${ }^{196}$ The trade secret lasts as long as substantial secrecy can be maintained. ${ }^{197}$

The United States likely has the most well-developed trade secret laws in the world. ${ }^{198}$ The United States has legislation designed along a torts model to prevent and redress misappropriations of trade secrets. ${ }^{199}$ Other jurisdictions, such as the United Kingdom, have relied more heavily on doctrines derived from the common law and equity, such as breach of

189. Lynn Sharp Paine, Trade Secrets and the Justification of Intellectual Property: A Comment on Hettinger, 20 PHIL. \& PUB. AfF. 247, 250-51 (1991).

190. See Lipton, Commercial Information, supra note 54, at 9-15.

191. LEAFFER, supra note 81, at 37.

192. Id.

193. Id.

194. 35 U.S.C. $\S 154(a)(2)(2000)$.

195. LEAFFER, supra note 81 , at 38 .

196. Id.

197. Id.

198. For an overview of trade secret law, see Bouchoux, supra note 74 , ch. 22 . See also James Hill, Trade Secrets, Unjust Enrichment, and the Classification of Obligations, 4 VA. J.L. \& TECH. 2, 6 (1999); Lipton, Commercial Information, supra note 54, § 2.1.

199. See, e.g., UnIF. TRAdE SECRETS ACT (amended 1985); Federal Economic Espionage Act, 18 U.S.C. $§ 90$ (1996); Ruckelshaus v. Monsanto Co., 467 U.S. 986 (1984). 
contract and breach of confidence, to protect valuable commercial confidences. $^{200}$

The main difference between these approaches is that the United States courts and legislatures have treated trade secrets as a form of property ${ }^{201}$ that is capable of being appropriated by a wrongdoer. In contrast, lawmaking bodies in most other jurisdictions, rather than treating information as the misappropriated property of the victim, base remedies on the nature of the relationship between the parties. ${ }^{202}$ This latter approach is difficult to apply to third party misappropriations of valuable information where the victim and the wrongdoer lack any contractual or equitable relationship. ${ }^{203}$

However, although U.S. trade secret law seems to protect proprietary, rather than purely contractual, interests, it may be more similar to the law in some other jurisdictions than it might first appear. As Professor Leaffer has noted:

Trade secrets have the attributes of property, and can be licensed, taxed, and inherited. But if an attribute of property is the right to exclude others from using it, the trade secret is a weak form of property protection. A trade secret can only be enforced against improper appropriation, such as theft by an industrial spy, or a breach of a confidential relationship not to divulge the trade secret. This is why it is often said that trade secret [sic] protects a relationship rather than a property interest. ${ }^{204}$

Thus, the main advantage of the American legal approach to trade secrecy may be that trade secrets can be more easily dealt with as property in a transactional sense ${ }^{205}$ than is possible in other jurisdictions. This is because the United States has accepted the "property" label. In other jurisdictions, such as the United Kingdom, a trade secret is, at best, labelled "quasi-property."

200. See, e.g., CORNISH, supra note 182, at 301-06.

201. Ruckelshaus, 467 U.S. at 1002.

202. See Lipton, Commercial Information, supra note $54, \S 2.1$.

203. Jill MCKeOUgh \& ANDREW Stewart, InTEllectual Property IN AUSTRALIA, 85-86 (2d ed. 1997).

204. LEAFFER, supra note 81 , at 38 (emphasis added); see also NiMMER, supra note 37, I 3.02[1]; Paine, supra note 189, at 256-58. Professor Litman has also noted that a proprietary label is often attributed to information to ensure ease of transferability/alienation of the information, despite the fact that property theory is generally not a good basis for explaining legal rights in information. See Litman, supra note 28 , at 1283 .

205. Id. at 1296. 


\section{The Secrecy Requirement}

The question of just how secret a trade secret must be to acquire legal protection is important to the present discussion. As Professor Leaffer notes, absolute secrecy is not required, but the more widely the information is used in the relevant industry, the less likely it can be protected as property. ${ }^{206}$ In determining trade secrecy, courts will take into account: (a) the extent to which the trade secret holder's employees know the subject matter, ${ }^{207}$ and (b) the extent of measures taken to guard the subject matter's secrecy. ${ }^{208}$

These factors significantly limit the relevance and usefulness of trade secret law to protect the content and constituent software of commercially valuable databases. ${ }^{209}$ The whole point of a database is to make content available, usually for a fee, to members of the public who are not necessarily limited to a particular industry. Although contracts can be used to limit the end-user's use of the content and to maintain some secrecy, these contracts face the drafting and enforcement problems outlined above.

Courts are unlikely to find that materials intended for broad dissemination meet the requisite secrecy. This is so, even if the materials are disseminated for a fee and protected by confidentiality clauses that limit the end-user's uses of the data. ${ }^{210}$ Furthermore, in this context, customer confidentiality clauses may be suspect if obtained through a "shrinkwrap" or "clickwrap" license. The plaintiff's customers may not read the license, and such licenses are still of questionable enforceability despite the enactment of UCITA in several jurisdictions within the United States. ${ }^{211}$

There have also been significant concerns raised about the effectiveness of trade secret law to protect computer software that is distributed to the public. Software components of a database made

206. LEAFFER, supra note 81 , at 38 .

207. Id.

208. Id.

209. See MANN \& WINN, supra note 61 , at 377.

210. Id.

211. See also Ajay Ayyappan, UCITA: Uniformity at the Price of Fairness? 69 FORDHAM L. REV. 2471, 2493-95 (2001); Ingrid Michelsen Hillinger, Consumer Protection Rules In and Around the Uniform Computer Information Transactions Act, 649 PLI/PaT 401, 405-08 (2001); Carlyle C. Ring, Jr., UCITA: Contract Rules for Information Commerce, 649 PLI/PAT 45, $50-51$ (2001); Michael L. Rustad, Making UCITA More Consumer-Friendly, 18 J. MARShall J. COMPUTER \& INFO. L. 547, 578 (2000). 
available to the public are vulnerable to reverse engineering. Trade secret, like copyright, law permits reverse engineering provided that access to the software was not obtained illegally. ${ }^{212}$ In many cases, database content can also be discovered by reverse engineering the software, or simply through computer hacking. ${ }^{213}$

For the above reasons, trade secret law will likely have limited application or usefulness in protecting databases from unauthorized access, use, and disclosure. That trade secrecy law is far from uniform internationally and within the United States simply compounds the problems. For example, not all U.S. states have adopted the Uniform Trade Secrets Act and those that have, have not enacted it uniformly. ${ }^{214}$ This non-uniformity within the United States will not be solved by the enactment of the Economic Espionage Act in 1996 as a federal criminal law dealing with trade secret misappropriation. This federal statute creates new criminal penalties for trade secret misappropriation but does not preempt non-uniform state law in state civil court cases. ${ }^{215}$

The federal criminal legislation will prove useful (and indeed has already proven useful) in many cases of trade secret misappropriation because the victim of a misappropriation will save time and money by having the government pursue the offender. However, disadvantages include the potential lack of monetary remedy for the victim. And federal prosecutors may not pursue database cases, particularly if they foresee problems with defining database contents as trade secrets for the reasons identified above.

International trade secret law is also far from uniform. As noted above, courts in jurisdictions such as the United Kingdom have based their protection of valuable commercial confidences on the law of contracts and breach of confidence, ${ }^{216}$ despite calls from the Law Commission to enact specific trade secret legislation. ${ }^{217}$ Other jurisdictions throughout the European Union have taken varied approaches to the legal protection of

212. See, e.g., LEAFFER, supra note 81, at 109; Reichman \& Samuelson, supra note 9, at $59-60$.

213. LEAFFER, supra note 81 , at 109.

214. See Nat'l Conference of Commissioners on Uniform State Law, A Few Facts About the Uniform Trade Secrets Act, (on file with the author), available at http://www. nccusl.org/nccusl/uniformact_factsheets/uniformacts-fs-utsa.asp (last visited June 18, 2002).

215. 18 U.S.C. $\S 1838$ (1996).

216. See CORNISH, supra note 182, at 301-07.

217. Legislating the Criminal Code: Misuse of Trade Secrets (UK Law Commission, Consultation Paper No. 150, 1997), available at http://www.lawcom.gov. uk/351.htm. 
trade secrets despite the fact that the aim in each case is to protect the value of commercial information where all efforts have been made by its "owner" to retain secrecy. ${ }^{218}$

Because of trade secrecy law's national and international divergence and at its inherent shortcomings at protecting databases, trade secret protection is unlikely to be the solution to the problems faced by digital database makers. An alternative form of protection is necessary. ${ }^{219}$

\section{Sui Generis Database Protection Laws: Property Versus Tort}

\section{Existing Approaches to Sui Generis Database Legislation}

Many scholars have recognized the need for a new form of database protection law outside of contract, patent, copyright, and trade secret laws. ${ }^{220}$ While Professors Reichman and Samuelson criticized early attempts at drafting sui generis database protection legislation, they agreed that there was a need for new approaches to the issue because existing laws failed to address the realistic commercial needs of database producers. $^{221}$

Accepting, as many scholars do, that there is some need to create a legal approach to protecting commercially valuable databases as a form of property or quasi-property, ${ }^{222}$ the question then becomes "what form should such a law take?" To date, the debate has focused on two broad approaches to database protection. The first, the "property model," involves the protection of valuable database contents under a new form of

218. Brown, Bryan, \& Conley, supra note $40,177$.

219. It is interesting that the enactment of the Electronic Espionage Act in 1996 might be evidence of the need for enhanced government monitoring and regulation of information property rights, albeit through the criminal justice system in this case. Clearly domestic and international market forces were not ultimately regarded by Congress as sufficient to regulate the exploitation and dissemination of valuable trade secrets, particularly in international commerce.

220. See, e.g., Hughes, supra note 8, at 86-98; Reichman \& Samuelson, supra note 9, at 137.

221. Reichman \& Samuelson, supra note 9, at 137.

222. Id.; see also Austin, supra note 52, \63; Dennis S. Karjala, Misappropriation as a Third Intellectual Property Paradigm, 94 ColuM. L. Rev. 2594, 2594-95 (1994); Wolken, supra note 67 , at 1268-70. However, it should be noted for completeness that there are those who have raised arguments against database protection citing in support of this view issues such as: (a) the fact that the information industry is growing dramatically under the present system; (b) because of the pace of technological change, any new legislation could be obsolete before it took effect; and, (c) the undesirability of commodifying information and limiting free access which has, until recently, been the cornerstone of the digital revolution: See Austin, supra note 52, 91 60-61; Brown, Bryan, \& Conley, supra note 40 , $19795-110$. 
intellectual property right that grants proprietary protection over database contents. ${ }^{223}$ The second approach, the tort/misappropriation model, bases the protection of a database's inherent value on the economic impact caused by a second-comer in a market "free riding" on the work of the original database producer. ${ }^{224}$ This approach aims to prevent unfair conduct in a market without expressly creating "property rights" in database contents. ${ }^{225}$

The distinction between the two models is somewhat spurious. By definition, the tort/misappropriation model implies some sort of property rights, even if the rights are weaker or less absolute than those contemplated under the property model. For example, U.S. trade secret law uses a tort/misappropriation approach to protect the value of commercial information. ${ }^{226}$ However, this law also clearly involves property rights. Although legislation does not necessarily describe trade secrets as property, it implies that trade secrets are a form of intangible intellectual property. ${ }^{227}$ It is impossible to have a tort law based on misappropriation of property without accepting in the first place the existence of the property.

A debate that focuses on choosing between these two approaches is fruitless, and will likely only lead to inadequate draft legislation like that now being debated in the United States. ${ }^{228}$ The main distinctions between the two approaches are the duration of a database's legal protection and the basis for calculating database infringement damages. These issues are important but not as fundamental to the development of new law as recognizing the appropriate foundations of the law from first principles, in terms of precisely what interests are being protected and on what basis. Once the basic foundations of a new law are established and its structures

223. An example is the United Kingdom's adoption of the principles of the E.U. Database Directive. A broad "personal property" right is expressly created in The Copyright and Rights in Databases Regulations, (1997) SI 1997/3032, R. 13(1) (Eng.).

224. Id

225. Reichman \& Samuelson, supra note 9, at 137-63.

226. Id. at 60-61.

227. The terms "property" and "property right" do not appear in legislation such as the Uniform Trade Secrets Act and Economic Espionage Act, 18 U.S.C. $\S \S 1831-1839$ (1996). However, the legislation clearly contemplates "ownership" of legal and equitable interests. See, for example, the definition of "trade secret" in 18 U.S.C. § 1839(3)-(4).

228. Both the Antipiracy Bill and the Consumer and Investor Access Bill arguably owe too much to their origins in copyright law to be effective in the database context, even though the former may be described as a "proprietary" model and the latter as a torts/misappropriation model. The following discussion explains why these approaches are not satisfactory and suggests directions for law reform in this area that diverge from the approaches taken in these bills. 
clarified, it is relatively simple to create appropriate terms of protection and damage calculations to meet the needs of the market, and of society, at the relevant time.

Because both models involve the commodification of databases as property to some degree, fears about over-commodification of information beyond the reasonable needs of commercial database producers may arise. It is more important, however, to ascertain with a focus on relevant commercial activities the extent to which databases can and should be commodified.

The property versus tort/misappropriation debate might help inform the secondary debate on periods of protection and calculation of damages. However, the debate does not resolve the primary questions regarding the appropriate foundations of a new legal system for databases. Clearly, property rights in information compilations will be part of any new legislative package, whether expressly or by implication. What is important, however, is working out how to create, tailor, and monitor rights appropriately to meet the needs of the information society.

\section{The Consumer and Investor Access to Information Bill}

To date, examples of both the tort/misappropriation approach and the proprietary model for database protection legislation have been drafted. The E.U. Directive, which is discussed in the next section, is a clear example of the proprietary approach, and several draft United States database laws are modeled on this law. The only existing model of database protection legislation that uses the tort/misappropriation approach is the Consumer and Investor Access Bill. ${ }^{229}$ The Consumer and Investor Access Bill has never become law. However, despite its unenacted status, it is a useful example of the approach commentators have had in mind when describing a tort/misappropriation model for database protection legislation.

The Consumer and Investor Access Bill defines database broadly, as described in Part I. However, in contrast to the proprietary approach, it does not expressly create proprietary rights in a database. It prohibits the public sale or distribution of a database that (1) duplicates another database collected and organized by another person, and (2) is sold or distributed "in commerce in competition with" the original database. ${ }^{230}$ Although no express proprietary right in a database is created here, an implied proprietary or quasi-proprietary right is arguably created. The

229. H.R. 1858, 106th Cong. (1999).

230. Id. $\S 102$. 
Consumer and Investor Access Bill's underlying assumption is that when a competitor wrongfully misappropriates the property of a database maker, that competitor should be required to compensate the database maker for resulting economic loss.

The Consumer and Investor Access Bill's prohibited activities are tightly restricted to sale or distribution in competition with the original database. This is a significant step towards restricting the reach of sui generis database protection law to reasonable commercial activity. The prohibition extends to sale and distribution of "duplicates of a database," connoting a database that duplicates a substantial part of another database. $^{231}$

The bill does not prohibit duplication or copying per se of the database contents, which distinguishes this law from the copyright model. ${ }^{232}$ However, it does carve out fair use exceptions that appear to have been modeled on copyright law. These exceptions include "permitted acts" relating to independent collections of information; ${ }^{233}$ news reporting; ${ }^{234}$ law enforcement and intelligence activities; ${ }^{235}$ and scientific, educational, or research activities. ${ }^{236}$

Thus, even though the Consumer and Investor Access Bill is drafted according to the tort/misappropriation model and addresses some of the concerns about database protection, it probably depends too much 'on copyright law to effectively balance the needs of database producers against public policy concerns.

The more database protection law relies on vague copyright concepts like "fair use" and "permitted exception" provisions, the more room there is for difficult questions regarding coverage of the law to arise. ${ }^{237}$ Courts

231. "Duplicate" is defined in the bill as connoting a database that is "substantially the same" as the original database and was "made by extracting information" from the original database. $I d$. $\S 101(2)$.

232. In any event, it is appropriate that copying of database contents not be proscribed under any new law. This issue is taken up in more detail below.

233. H.R. $1858 \S 103(\mathrm{a})$.

234. Id. § 103(b).

235. Id. $\S 103(\mathrm{c})$.

236. Id. $\S 103(\mathrm{~d})$. There are further exclusions from the scope of the prohibition set out in section 104 relating to government information, databases related to effective Internet communication, computer programs, ideas, facts, procedures, systems, concepts, methods of operation, principles, discoveries, and subscriber list information. See id. $\S 104$.

237. However, it might be argued that many of the fair use exceptions in the Consumer and Investor Access Bill would not be likely to come into play in practice if the Bill was ever enacted into law. This is because most of the exempt uses are not likely 
have difficulty determining the scope of fair use exceptions and often rule inconsistently. ${ }^{238}$ For this reason, exceptions should not be too heavily relied upon in any new database law. Greater legislative guidance on the initial limitations of the rights in question will minimize the need to focus on fair use exceptions because fewer cases will arise on these exceptions if the rights in question are more tightly restricted in the first place. ${ }^{239}$

Obviously, any sui generis database protection law must rely to some extent on exceptions to prohibited conduct. However, the more these exceptions are simplified by tightly restricting the concept of a protected database, the more efficient the operation of the legislation will be. It is thus necessary to have a clear and easily discernible relationship between the definition of database and any prohibited conduct involving databases.

The Consumer and Investor Access Bill quite satisfactorily limits the scope of the prohibitions to certain commercial activities. However, broadly defining "database" and then prohibiting clear-cut activities involving databases is not the same thing as tightly limiting the definition of a database initially and then clearly relating the definition to the prohibitions. The latter approach focuses the legislation much more effectively on a limited range of information products from the beginning. The permitted activities involving those databases are also automatically limited because of the more restricted scope of database definition. ${ }^{240}$

\section{The E.U. Approach}

The E.U. Directive is the only model of sui generis database legislation that has been enacted in any jurisdiction. The E.U. Directive is purely a proprietary rights model that expressly creates broad, generic rights in the exploitation of database contents, then carves out some fair

to be in commercial competition in any event, and are therefore unlikely to infringe the main prohibition in the first place. On another point, it should also be noted that there are some additional problems with the Consumer and Investor Access Bill as currently drafted, not the least of which is $\S 106(\mathrm{~b})$ which deals with limitations on liability where a database owner is said to have "misused the protection" afforded by the legislation, with some broad general guidance as to how the concept of "misuse of protection" is to be defined.

238. DAVID, supra note 69, at 14-15; LEAFFER, supra note 81, at 428.

239. In other words, the legislative grant of lesser rights must, by definition, give rise to less litigation about the scope of those rights. This is particularly the case if the assertion of a right requires registration, supported by documentation that is investigated by an expert body of administrators.

240. As suggested in the early part of this discussion, the concept of database could be limited in the definition section of any new legislation expressly to exclude things like: (a) paper-based databases, (b) databases developed primarily for educational, scientific, or technological use, (c) databases developed primarily for personal use, etc. 
use exemptions from liability. As set out below, there are many problems with this model. However, it should be kept in mind that a tort/misappropriation model may generate many of the same problems. ${ }^{241}$

The European Union's original plan was more akin to a tort/misappropriation model that protected databases to prevent free riding in the database industry by competitors who unfairly extracted database contents. ${ }^{242}$ Early versions of the E.U. Directive also included provisions requiring compulsory licensing of databases that were the sole source of certain information within an industry. ${ }^{243}$ These provisions were designed to give database makers the head start they deserved for being the first players in the market, while allowing others to enter the market at a reasonable market cost. The provisions were not originally designed to give the database maker an exclusive property right in the fruits of its labors. ${ }^{244}$ However, determined lobbying by those in favor of protectionist strategies for the global information infrastructure - publishers and some E.U. and U.S. officials - successfully transformed the original E.U. proposal from "a relatively weak liability regime to a strong exclusive property right." 245

\section{The Current E.U. Framework As Adopted in the United Kingdom}

The final version of the E.U. Directive shows the advantages and disadvantages of its approach to sui generis rights in databases. Examining the operation of the Directive throughout the European Union, Professors Reichman and Samuelson have expressed various concerns:

1) The final version of the E.U. Directive moves away from notions of unfair or unauthorized uses of database contents, instead favoring the exclusive right of database makers to prevent

241. This is why the thrust of this Article is to suggest some new approaches to the question of database protection legislation, rather than to enter the debate about whether or not property rights should be created in databases.

242. See Reichman \& Samuelson, supra note 9, at 80-82.

243. Id. at 82 . Sole source information providers are likely to raise difficult issues whatever form of law is ultimately enacted in any jurisdiction. It is arguable that however any new law is framed, it must contain specific provisions that deal adequately with these issues to prevent commercial monopolies of information that should be accessible in the public domain. The appropriate mechanism to deal with this may well be compulsory licensing, perhaps with determinations of the need for licensing in a particular case, and appropriate amounts of royalties to be determined by a specially constituted body of experts in the field. This could be set up under any new legislation.

244. Id. at $80-83$.

245. Id. at $75-76,84$. 
extraction and re-use of a substantial part of a database's contents (evaluated quantitatively or qualitatively). ${ }^{246}$

2) The Directive's fifteen-year term for the property right in a database can apparently be indefinitely extended. ${ }^{247}$

3) The Directive does not require creativity or novel contribution to attract database protection only a substantial investment in obtaining, verifying, or presenting database contents. ${ }^{248}$

4) The Directive offers no guidelines to determine the level of investment required to justify the property right in the database or to extend the duration of an existing right. ${ }^{249}$

5) The Directive's database right potentially erodes the idea/expression dichotomy from copyright law. ${ }^{250}$

6) The Directive's potentially unlimited term of protection, coupled with the strong proprietary nature of the protection and the lack of significant fair use exceptions to the property right, ${ }^{251}$ dramatically

246. E.U. Directive, supra note 27, art. 7; Reichman \& Samuelson, supra note 9, at 84-85.

247. E.U. Directive, supra note 27, art. 10; LLOYD, supra note 97, at 189; Reichman \& Samuelson, supra note 9 , at 84-85.

248. E.U. Directive, supra note 27, art. 7; Reichman \& Samuelson, supra note 9, at 84-85.

249. Reichman \& Samuelson, supra note 9, at 84-86.

250. Id. at $87-90$.

251. Article 9 of the E.U. Directive provides some fair use exceptions to the database right relating to: (a) private use of the contents of a non-electronic database, (b) use for illustration for teaching or scientific research as long as the source is indicated and there is a non-commercial purpose, and (c) use for public security or an administrative or judicial procedure. E.U. Directive, supra note 27, at art. 9. However, the Article is not mandatory; that is, E.U. Member States have the option whether or not to enact any of these exceptions into domestic law. This Article differs from the original draft WIPO Treaty on databases (which was never brought into force). Article 5(1) of the Draft Treaty provides that: "Contracting Parties may, in their national legislation, provide exceptions to or limitations of the rights provided in this Treaty in certain special cases that do not conflict with the normal exploitation of the database and do not unreasonably prejudice the legitimate interests of the rightholder." WIPO, Draft Treaty, supra note 86, at art. 5(1). However, it should be noted that the Treaty in general takes a different approach than the E.U. Directive. It does not expressly grant a property right in a database. Rather, Article 3(1) of the Draft Treaty gives the maker of a database the right to "authorize or prohibit the extraction or utilization of its contents," apparently leaving it to Contracting States to decide how to achieve this in practice. Id. at art. 3(1). Article 4(2) of the Draft Treaty contemplates that rights granted under the treaty shall be freely transferable and this may, in fact, connote an intention to create a property right in a 
erodes the public domain and potentially over-commidifies information products. ${ }^{252}$

7) The final Directive's deletion of the compulsory licensing provision for sole source providers of information creates nearly insurmountable barriers to entry for potential second-comers into information markets and secondary markets. ${ }^{253}$ The compulsory licensing provision had been the one aspect of government oversight contemplated in the E.U. database debate.

Looking at the way in which the E.U. Directive has been transposed into national law in various E.U. Member States, most of these concerns appear justified. For example, provisions in the United Kingdom's 1997 domestic legislative enactment--the Copyright and Rights in Databases Regulations 1997 ("CRDR")—raise precisely these concerns. ${ }^{254}$

The CRDR defines a database broadly to include both paper-based and electronic databases. ${ }^{255} \mathrm{~A}$ "database right" is created in a database if there has been a "substantial investment in obtaining, verifying or presenting the contents of a database." $" 256$ Thus, in keeping with the aims of the legislation, there is no reference to creativity or innovation other than that required in section $3 \mathrm{~A}(2)$ of the CDPA in relation to copyright protection for a database.

A person infringes a database right if that person extracts ${ }^{257}$ or reutilizes $^{258}$ all or a substantial part ${ }^{259}$ of the contents of a database without

database, as arguably might the fact that the treaty also contemplates (in Article 8) that a specific term of protection would be established in years in relation to the rights granted to a database maker. $I d$. at art. 4(2). The grant of rights for a particular period of time would seem to be in keeping with notions of proprietary monopolies limited in time as is the case with copyright and patent.

252. Reichman \& Samuelson, supra note 9, at 87-90.

253. Id. at 86 .

254. Copyright and Rights in Databases Regulations, (1997) SI 1997/3032 [hereinafter CRDR].

255. The definition of "database" for these purposes is found in the CDPA. See CDPA, supra note 80, § 3A(1); LLOYD, supra note 97, at 177-78.

256. CRDR, supra at note 254, at R. 13(1).

257. "Extraction" means the permanent or temporary transfer of database contents in any form to another medium by any means. Id. at R. 12(1).

258. "Reutilization" means making the database contents available to the public by any means. Id.

259. As contemplated in the E.U. Directive, a "substantial" part of a database's contents is defined in both quantitative and qualitative terms. Id. 
the consent of the owner of the database right. ${ }^{260}$ In this context, the repeated and systematic extraction or reutilization of insubstantial parts of a database's contents may amount to the extraction or reutilization of a substantial part of those contents. ${ }^{261}$

CDPA appears to give strong proprietary rights to database makers The infringement provisions are broad, and the fifteen-year protection term ${ }^{262}$ is extendable upon "substantial" changes to the contents of the database, including changes from successive additions, deletions, or alterations. ${ }^{263}$ These provisions exemplify the operation of some of the concerns voiced by Professor Reichman, Professor Samuelson, and other commentators. $^{264}$

The English database right is limited by exceptions allowing a lawful user to use a database. The CDPA defines "lawful user," rather unhelpfully, in Rule 12(1) as a person who has a right to use the database, whether under a license to do any of the acts restricted by the database right or otherwise. For example, a lawful user of a database that has been made available to the public is entitled to extract or reutilize insubstantial parts of the database contents for any purpose. ${ }^{265}$ Additionally, a lawful user may extract a substantial part of such a database as an illustration for teaching or research but not for any commercial purpose provided that the source is indicated. ${ }^{266}$

This example again supports avoiding the copyright model altogether when drafting sui generis database protection. That is, it is important to avoid creating relatively broad rights and then struggling to ascertain the permitted fair use exceptions to those rights. Again, it is easier to clearly and tightly restrict the creation of the rights in the first place.

One way to achieve this would be to limit the definition of database for the purpose of any sui generis legislation and tailor relevant rights and liabilities to reasonable commercial activities concerning the database as so defined. Government scrutiny and supervision in the creation and commercial exploitation of the database in clearly identified markets may also assist here. Such an approach would take pressure off the legislators

260. Id. at R. $16(1)$.

261. Id. at R. 16(2).

262. Id. at R. 17(1)-17(2).

263. Id. at R. 17(3).

264. See, e.g., DAVID, supra note 69, at 22-23; Austin, supra note 52; Brown, Bryan, \& Conley, supra note 40; Davison, supra note 130, at 283-84.

265. CRDR, supra at note 254, R. $19(1)$.

266. Id. at R. 20(1). 
to delineate workable fair use provisions, a task which has proven difficult in both the copyright and database right context. ${ }^{267}$

Many of these comments apply equally to a tort/misappropriation model of database protection legislation. Any model may attract such criticism where the rights created in the first place are broad because the definition of database is too broad or vague. This may be the case even if the actual database rights granted under a tort/misappropriation model are weaker rights than those granted under a pure proprietary model.

Thus, a tort/misappropriation model of database protection that has even the indirect effect of creating implied proprietary rights in a broad array of databases (including educational, scientific, personal, or paperbased databases) may well experience similar difficulties with delineating permitted fair use exceptions as an expressly proprietary model of database protection. This is arguably the case with the Consumer and Investor Access Bill even though its prohibitions on database use are significantly more limited than those in the E.U. Directive.

Returning to the "lawful use" exceptions in English database law: there is no definition in either the CDPA or CRDR of "commercial purpose" relating to the "lawful use" provisions. Thus, difficult interpretative questions may arise as to whether particular teaching and research activities involving databases are permissible. ${ }^{268} \mathrm{~A}$ commercial purpose may be unclear in an era in which institutions such as universities have the potential to commercialize to an extent previously unpracticed research products and teaching materials in competition with other institutions. ${ }^{269}$

In any event, it also seems possible that the CRDR provisions allowing extraction of database contents as illustration for teaching or research and not for any commercial purpose may have "illustration" interpreted narrowly. It is likely difficult to use database contents for illustration without also using them for broader research and educational purposes that led to the need for the illustration in the first place. ${ }^{270}$

\section{Critiquing the E.U. Approach}

In summary, a brief look at the United Kingdom's transposition of the E.U. Directive into domestic law raises concerns about the creation of

267. DAVID, supra note 69, at 6; LEAFFER, supra note 81 , at 428 .

268. NAT'L RESEARCH COUNCIL, supra note 55, at ch. 3.

269. Jacqueline Lipton, The E.U. Database Right and University Teaching Materials, 1 J. INFO., L. \& TECH (2002), available at http://elj.warwick.ac.uk/jilt/02-1/lipton.html (last visited June 18, 2002) [hereinafter Lipton, E.U. Database Right].

270. DAVID, supra note 69, at 23; Reichman \& Samuelson, supra note 9, at 92-93. 
broad database rights with vague and narrow exceptions. The structural reason for this is the broad definition of database, leading to a potentially broad array of prohibited conduct, which is only tempered by vague "lawful use" exceptions.

Sui generis database protection law throughout the European Union is still in its nascent stages and time will tell how serious these problems will ultimately become in practice. ${ }^{271}$ Therefore, it may not be too late for some legislative changes to be made in the European Union if it can be demonstrated that a more desirable model of database protection legislation is possible, particularly if the United States subscribes to such a model. ${ }^{272}$

Many of the commentators who have criticized the operation of the new database rules throughout the European Union hail from the United States. One reason for this is that recent moves by E.U. Member States to enact database legislation raise an imperative for the U.S. Congress to take similar action. If Congress fails to do so, businesses may perceive greater protection for their databases in Europe and may then set up operations in E.U. Member States rather than in the United States. ${ }^{273}$ Indeed, given the perceived problems with current E.U. measures, many American commentators hope that Congress does not "make the same mistakes" as the European Union. ${ }^{274}$

\section{NEW DIRECTIONS IN DATABASE PROTECTION}

The best model for database protection legislation may yet emerge from the national or international debates. The current debate has been too closely tied to copyright models simply because the need for database protection legislation has been based on the perceived failings of copyright law to adequately protect digital database contents. Models based too closely on the law of trade secrets and unfair competition will also likely be ineffective for the same reasons previously discussed.

Future discussions should take a new turn altogether, leaving the inadequacies of copyright law aside and focusing purely on the realistic

271. Early case law and commentary suggests that some difficult interpretative questions about the scope of the legislation amongst E.U. Member States are already emerging in practice: British Horseracing Bd. Ltd. v. William Hill Org. Ltd., [2001] R.P.C. 31, [2001] 2 C.M.L.R. 12 (Eng. Ch. Pat. Ct.), available at 2001 WL 98034; Colston, supra note 12.

272. Colston, supra note $12, \S \S 5,5.3$.

273. Boyarski, supra note 104 , at $907-08$

274. Id.; Reichman \& Samuelson, supra note 9, at 95. 
commercial needs of database producers and on the needs of society, domestically and internationally.

We need a completely new approach that looks to the operation of trademark, and to some extent, patent law as models involving the commercialization of information property rights, accompanied by significant government oversight. As argued in the next section, laws creating commercially exploitable rights over non-creative information products require government regulation and monitoring because of the dangers inherent in leaving it to the market to monitor the exploitation of often mundane information and ideas whose value lie not in their creativity, but in their comprehensive collation.

\section{A. Elements for a Comprehensive Database Protection Law}

American businesses may currently be disadvantaged vis-à-vis their E.U. counterparts because they are less able to protect database contents and because the E.U. Directive does not provide reciprocal protection to the United States. ${ }^{275}$ Today, E.U. businesses can arguably extract an American database's contents for reutilization in their own business and obtain a database right for this copied product while facing limited or no legal redress from the original American database maker. ${ }^{276}$ Given the absence of any empirical evidence, it is unclear whether this is currently a problem. Furthermore, American database producers can use restrictive contracts and technological measures to protect database contents from much unauthorized activity.

If the U.S. Congress, however, fails to act on database protection, it may eventually be forced to do so as part of a global harmonization initiative. By failing to take prompt action, the United States might be relegated to following the lead of other countries, regardless of how irrelevant or unattractive those laws may be to the American businesses. ${ }^{277}$

The model I propose for the United States could ultimately be adapted internationally. This model focuses on the registration and commercial exploitation of databases, and overcomes some of the weaknesses inherent in current approaches. It uses mechanisms borrowed from trademark and patent law to create property rights in data compilations in order to monitor, control, and limit the exercise of the rights. Furthermore, it

275. See E.U. Directive, supra note 27, art. 11; Boyarski, supra note 104, at 907-08.

276. In fairness, it should be noted that several commentators have suggested that the argument in favor of legislation in the United States based on the fact that American database producers will now be disadvantaged vis-à-vis the European Union is not very convincing in practice. See NAT'L RESEARCH COUNCIL, supra note 55, at ch. 3.

277. See Wolken, supra note 67 , at 1305. 
incorporates some government oversight of the database rights and their commercial exploitation in order to provide significant value to private and public interests alike. Government oversight is not a novel approach to the creation and commercial exploitation of valuable information property rights. Such oversight is already found in trademark law and, to some extent, patent law. ${ }^{278}$

The following comments offer suggestions to shift the debate away from a focus on copyright law and the perceived divide between the property and tort/misappropriation approachs.

Reforming database protection law raises closely interrelated issues: (a) the definition of database; (b) the rights that may be given to database producers; (c) necessary exceptions to those rights, including fair use provisions and, more importantly, compulsory licensing; (d) registration of interests in databases; (e) investigation of business plans showing intention to exploit a database in one or more commercial markets; (f) dispute resolution mechanisms. Obviously, government monitoring could be required for many functions such as compulsory licensing, administrative orders releasing certain information to the public or to private individuals, examination of business plans prior to registration, and some dispute resolution.

It should be possible to draft a new law that clearly confines itself to protecting the contents of only commercial databases against unauthorized access, duplication, use, or distribution. ${ }^{279}$ To do so, the definition of a commercial database should focus on commercial exploitation in identified markets and exclude certain non-commercial databases. The law should tightly control and limit prohibited activities to the commercial context. The law should only be broad enough to protect those actually investing time and money into a database they intend to commercialize, enabling them to reap the rewards of their entrepreneurial activities.

We should move past debating whether legislatures should create property or quasi-property rights in new intangible information products such as databases. Rather, we must accept that any legislative attempt to protect rights in such products will either expressly or by implication

278. Trademark and patent systems the world over require some level of government examination prior to registration of a relevant right. The American trademark system also requires various affidavits to be filed relating to good faith use of the trademark in question.

279. The query needs to be raised here, and is taken up below, whether duplication should be prohibited under any new law. This may make the model seem too much like a new version of copyright law and, in any event, may go well beyond the realistic commercial needs of database producers. 
create a new form of legal property. Balancing those rights against competing public and private interests should be the core debate.

The thoughtful and careful creation of new property rights can help find and maintain an appropriate balance among the interests of creators, users, and society. Property rights serve as a useful mechanism to prevent undesirable incursions into the public domain of information and ideas. They are only dangerous and undesirable when created without sufficient thought to the necessary needs of those lobbying for them and the obligations imposed on those asserting such rights. These obligations may involve submission to government examination of applications for the property right, compulsory licensing, and other limitations on the right's commercial exploitation. Governmental control and monitoring of information property rights have proven successful in patent ${ }^{280}$ and trademark law. ${ }^{281}$ Compulsory licensing has also been used for some classes of musical works in the United States. ${ }^{282}$

Database protection law should provide a safe environment that encourages people to produce and commercially exploit valuable databases without creating unfair monopolies over mundane information. To achieve this, new law must address which databases it will protect; how it will create, qualify, and administer such protection; what is permitted and prohibited; and how long protection will last.

\section{B. Criteria for Protection}

A database may have multiple purposes, one of which may be commercial. For example, a database may be created in an educational or scientific setting with or without the intent to commercialize it. If created

280. Patent law has traditionally required inventors to submit to an examination of their claimed invention and to have their patented invention published on the relevant patent register(s) for ultimate consumption in the public domain when the patent term expires. Additionally, compulsory licensing of certain patents has been utilized in some jurisdictions such as the United Kingdom. See Patent Act, 1977, §48 (Eng.). And is required in the United States by TRIPs with respect to certain pharmaceuticals. See Dora Kripapuri, Reasoned Compulsory Licensing: Applying U.S. Antitrust's "Rule of Reason" to TRIP's Compulsory Licensing Provision, 36 NEW ENG. L. REV. 669, $681-83$ (2002); Patrick Marc, Compulsory Licensing and the South African Medicine Act of 1997: Violation or Compliance of the Trade Related Aspects of Intellectual Property Rights Agreement?, 21 N.Y.L. SCH. J. INT'L \& CoMP. L. 109, 115-16 (2001); Joseph A. Yosick, Compulsory Patent Licensing For Efficient Use of Inventions, 2001 U. ILL. L. REV. 1275, $1278-79,1282(2001)$.

281. Trademark law requires public registration of a market in respect of one or more identified markets.

282. 17 U.S.C. $\S 115$ (2000) (providing for compulsory licensing for non-dramatic musical works). 
with the intent to commercialize, as many scientific and educational databases currently are, then the database should be protected by the law. If not, then it should not be protected.

The database protection model described here is intended to promote commerce and to balance this aim against the need to protect a vibrant public domain of information and ideas. Where a database is created without any commercial intent, it should be preserved as a public domain resource, particularly if it is created with the support of government funding. ${ }^{283}$ Where there is either a wholly or partly commercial purpose, the legislative scheme should assist with the commercialization objectives while preventing unfair commercial monopolies of information and ideas.

The law should not require that commercialization be the sole purpose for which a database has been created in order to attain protection. However, it should at least provide that a bona fide intent to commercialize a database be a significant purpose behind its creation. In identifying a bona fide intent to commercialize a database, the law should recognize that not all database producers necessarily plan to commercially exploit their databases immediately on creation. This is a difficult issue, because it runs contrary to law's goals to allow anyone to propertize information without actually commercializing it or imminently planning to commercialize it. Possibly, producers that create a database for exploitation at some future time should rely on trade secrecy and contractual non-disclosure agreements until they decide either to release the database into the public domain or to register and commercialize it as a protected database.

Legislators would also have to consider a compulsory licensing scheme for registered databases particularly for sole source information providers. Any new law should establish an administrative body to decide issues of compulsory licensing and to apply any legislative exceptions to database protection based on public interest considerations. The body should be empowered to order the release of information into the public domain or into the hands of private individuals such as scientists and educators.

Compulsory licensing is a difficult and contentious issue, particularly when people believe the government should not make decisions about commercial exploitation and access to valuable information. However, there may be no viable alternative. There is also a clear distrust of the market in this area, and significant concern about the commodification of

283. As noted above, open source licensing may be one way of ensuring that information released into the public domain remains in the public domain. 
information and ideas generally by market players. ${ }^{284}$ The same may be said of empowering an administrative body with the authority to make orders that certain information be released into the public domain or into the hands of named individuals for public interest purposes.

To inspire public trust of the administrative body and its procedures, the law should require the authority (a) to maintain some transparency in its decision-making functions; (b) to keep public records of its decisions; and (c) to hear from parties concerned with a compulsory license or a public information disclosure. Additionally, to achieve a breadth of expertise, the authority should include representatives nominated or appointed by different sectors of society, science, and commerce.

\section{The Stand-Alone Database Register}

Establishing a register of database rights ${ }^{285}$ to show ownership of a database would further promote the purpose of the law. As in trademark law, such a register would allow database Qwners to exploit their databases in commercial markets with at least some government examination and oversight. By recording the database producers' groundwork in compiling their products and tracking original data sources, the register serves as a central source for adjudicating database rights. Such registration and administration should be completely separate from existing intellectual property regimes such as the copyright, patent, and trademark registers; it should be a sui generis body specialized in overseeing database rights.

Establishing a stand-alone database register would help solve the problem of ascertaining if and at what time a database maker intended to commercialize its database. Surely, if a producer has put effort into the development of a database with the intent to profit, it is no great impediment to require the registration of the database rights.

The law might also require the database maker to specify in the registrer the markets in which it intends to commercialize the database. ${ }^{286}$

284. Jacqueline Lipton, Information Wants to be Property: Legal Commodification of E-Commerce Assets, 16 INT. REV. L COMP. \& TECH 53 (2002) (discussing moves in a number of jurisdictions towards the increasing propertization of information products) [hereinafter Lipton, Information Wants]; Reichman \& Samuelson, supra note 9, at 52-53 (discussing the concern about creating powerful property rights in databases in the United States; Therien, supra note 36, at 1029 (discussing concerns that the DMCA will overpropertize digital information if courts do not take an adequate stance on protecting "fair uses").

285. Wolken, supra note 67 , at 1296.

286. The register here might be supplemented with an "intent to commercialize" procedure for databases, not unlike the "intent to use" procedures found in the law of 
As with trademark law, the database law would not protect uses the maker fails to specify in the register. ${ }^{287}$ This specificity could safeguard the interests of those who want to use the information in secondary markets not in direct competition with the original database producer.

The legislation provisions setting out prohibited conduct could be expressly linked to the markets identified by the database right owner in the register. For example, the provisions could prohibit use of all or a substantial part of the database contents in any market specified in the register. If the legislation followed this approach, provisions may be necessary to ensure that a registrant does indeed use the database in the specified markets within a reasonable period after registration. Failure to do so might result in the loss of registration for that market.

Alternatively, infringement could be limited to uses of all or a substantial part of a registered database's contents in competition with the registrant in any market specified in the register. The inclusion of the "in competition with" requirement could prevent database producers from attempting to stifle activity in a market that it has not yet entered in order to reserve the market for itself. However, even this approach would benefit from also requiring the database right owner to enter a specified market within a particular time after registration or risk losing registration for that market. ${ }^{288}$

registered trademarks. See 15 U.S.C. $§ 1051$ (b) (2000); BouCHOUX, supra note 74, at 6566.

287. There is perhaps an imperfect parallel here with the way trademark registration systems tend to require an applicant for registration to identify the goods and services for which the mark is to be used. Protection under the relevant legislation will be granted for those goods and services. BouchouX, supra note 74 , at $47-52$. In the database case, it would not be goods and services that the applicant was required to note on the application for registration, but markets in which the applicant intended to exploit the database. In this regard, it may help if a domestic, or even international, classification system for relevant markets could be established, not unlike the WIPO Classification System for goods and services in trademark law. See WIPO, LIST OF CLASSES OF GOODS AND SERVICES ESTABLISHED BY THE NiCE AGREEMENT CONCERNING THE INTERNATIONAL ClassifiCATION OF GOODS AND SERVICES FOR THE PURPOSES OF THE REGISTRATION OF MARKS, (on file with author), available at http://wipo.org/madrid/en/index.html (last visited June 19, 2002).

288. This could be tempered by provisions that a delayed entry into a market might not result in loss of registration for that market if the database right owner can give a reasonable explanation to the administrative authority explaining the delay and if there would be no discernable negative effects on the market as a result of the delay coupled with a renewed grace period. 


\section{Investigation and Validation}

To ensure the integrity of the register, the model would also require an officer from the administering body to investigate and validate an application prior to registration. This is somewhat similar to patent law, although the process for database rights would involve different steps: (a) investigating other database rights registered in the same or similar markets to those claimed by the applicant, (b) ensuring that the database in question is at least almost ready for commercialization, and (c) checking that the applicant has bona fide plans to commercialize the database in the markets identified in the application.

When investigating other registered rights, the aim would be to secure rights in a database version against unauthorized reuse of its contents in that market, not to reserve all rights to use a database in a market to the first registrant. Thus, more than one market player could register a database right in the same market provided that no unauthorized extraction of contents had taken place in that market. If a second database producer has compiled a similar database to the original registrant by going back to the original information sources, the second producer should be equally entitled to claim and register a database right in the same market.

It could be a condition of registration that a database producer take all reasonable steps to identify its own database contents through the use of available technology like watermarks. With the use of watermark technology to track the original sources of data, database-producers should be able to provide evidence to the registration authority of unauthorized extraction or reuse. This could help resolve later disputes over unauthorized extraction or reuse when the competing databases use similar material in the same market. ${ }^{289}$

For example, Company A sets up an online travel agency with a database of airfares obtained by negotiating directly with airlines and then Company B does precisely the same thing. Both companies should be able to claim and register a database right in the same market, which differs from trademark law. In cases where one database producer is claiming unauthorized extraction or reuse of contents by another database producer in the same market, the register would evidence a clear record of compilation groundwork and the original sources of data, supplemented by

289. The database administration authority might also take on a "public education" function to advise people on how best to utilize available technology to protect databases. This is another useful function that government authority and oversight can add to its role in creating and protecting reasonable intangible property rights. See Lipton, Commercial Information, supra note 54, at 26-28. 
evidence of digital watermarking. ${ }^{290}$ The register should limit the scope of property rights in databases rather than create potential monopolies in database markets.

The second stage of the investigative process would ensure that applicants do not attempt to register ideas for databases in which they have not yet invested any time, effort, or capital. To satisfy the commercial intent requirement, the new rules should require applicants to show concrete business plans for the database in a particular market. Those who have not yet developed a database to the commercialization stage would likely opt to maintain trade secrecy until they are ready to register and commercialize the database. For those who have developed a database to the commercialization stage, it is not particularly onerous to require the disclosure of a business plan, particularly if such plans were kept confidential by the administrative body.

The law should include a provision that failure to commercialize a registered database within a certain period after registration would result in the loss of registration for the specified markets. This would encourage database producers to plan carefully for commercialization and only to register in markets in which they realistically intend to pursue commercial activities. This, in turn, would help prevent the chilling effect caused by a database producer registering in markets that it has no bona fide intention of entering. The timely commercialization provision could be supplemented by requiring affidavits of "continuing use" for database rights, not unlike the "affidavits of use" required in registered trademark law. ${ }^{291}$ This requirement would ensure the database's continued use, weed out abandoned and frivolous claims from the register, and quell the chilling effect described above.

\section{E. Duration of Database Rights}

The next step is to address the appropriate duration for a database property right. The alternatives are (1) a fixed term of years ${ }^{292}$ or (2) a duration based on the information's value and the effort put into compiling

290. Hector MacQueen, Copyright and the Internet, in LILIAN EDWARDS \& Charlotte Waelde, LAW AND THE INTERnet: A FrameWORK FOR EleCtronic COMMERCE $202(2000)$.

291. For trademarks, failure to submit the affidavit within the appropriate timeframe leads to loss of registration of the mark. 15 U.S.C. $\S 1058(a)-(b)(2000)$; BouCHOUX, supra note 74 , at 72 .

292. This tends to be associated with copyright/property models of database protection. 
the information. ${ }^{293}$ A fixed term of years is easier to draft, particularly if duration is measured from the date of registration. Under this scenario, the term should be significantly less than the E.U. Directive's extendable fifteen-year term. ${ }^{294}$ Three or four years of initial protection should be sufficient to give a database maker a head start over competitors. ${ }^{295}$

Even in the case of a continually updated electronic database, the term of protection should be limited to the term of the initial database because that protection is sufficient to give the database producer its head start. A database producer should not be able to claim ongoing proprietary rights in a database simply for keeping the database up-to-date. ${ }^{296}$ True, a competitor could wait until the database loses its protection and then copy both the original database and any updates. To prevent this, however, legislation could include provisions limiting what competitors can do with existing databases.

However, as a matter of public policy, a competitor should be able to copy a database and all updates after the original database producer has had its head start. In this case, the competitor may have to add some value to its copied database in order to draw customers away from the original database maker.

The second approach to duration of protection, which emphasizes the prevention of unfair competition by another commercial entity, may produce fairer results. ${ }^{297}$ This approach bases duration on the value of the database's information or the value of the effort put into compiling the information.

293. This tends to be associated with tort/misappropriation models of database protection.

294. See E.U. Directive, supra note 27, at art. 10.

295. On appropriate fixed terms of protection for sui generis database rights, see Austin, supra note 52, \86. See also Wolken, supra note 67, at 1301.

296. This is currently the situation in the E.U. where continually updating a database will effectively result in indefinite proprietary protection. The E.U. Directive provides that

[a]ny substantial change, evaluated qualitatively or quantitatively, to the contents of a database, including any substantial change resulting from the accumulation of successive additions, deletions or alterations, which would result in the database being considered to be a substantial new investment, evaluated qualitatively or quantitatively, shall qualify the database resulting from that investment for its own term of protection.

E.U. Directive, supra note 27 , at art. 10(3).

297. See, e.g., U.S. COPYRIGHT OFF., supra note 100; Reichman \& Samuelson, supra note 9 , at $139-44$. 
Such an approach also has serious drawbacks such as establishing who should determine the duration of protection and on what evidence. Presumably, a newly established administrative body would decide the duration for any given case. This body would gradually develop expertise in relevant market issues, including the fair duration for a database right. This administrative body should include experts with detailed knowledge of information markets from commerce, science, and education.

We must note that we are only considering how long one market player can assert proprietary rights against others. We are not necessarily balancing private and public interests. The database protection scheme advocated here would grant proprietary protection only to commercial databases. The key issue with duration is not how long a market player can own information and prevent public access to it, but rather how long a market player can assert a right to commercialize a database against a competitor.

Other aspects of the legislation would protect public interests by allowing the administrative body to order the release of information to the public domain or to one or more nominated individuals. Although the tasks are difficult, an administrative body with experts in relevant fields capable of examining expert evidence would tend to create better results than those created purely by market forces.

Another potential downside with this approach would be the difficulty maintaining a usable database register if databases attracted different terms of protection in different markets. Thus, a straight proprietary-based model for term of protection may be preferable, particularly if it was limited to an initial term of three or four years. Perhaps, this term could be extended on application to the registering authority with evidence to showing, for example, that unfair competition would occur in a market if the protection were not temporarily extended.

In this way, a limited proprietary model could be augmented by aspects of a tort/misappropriation model relating to the prevention of unfair competition or unjust enrichment. The possibility of drafting a law on this basis again shows that new sui generis database law need not be a choice between a proprietary and a tort/misappropriation model. Elements of each may be useful, and the two approaches may be merged if the focus is placed on developing appropriate foundations for the law from first principles. 


\section{F. Permitted and Prohibited Activities in Relation to Database Rights}

What should a database law permit and prohibit in order to achieve its purpose? Rationally self-interested database producers will want to allow access of database contents to authorized persons, prohibit others from access, and prevent unauthorized copying or distribution. ${ }^{298}$ The prohibitions set out by law should be limited to preventing competing commercial uses of a database in the markets for which it has been registered. This focus on competing commercial uses draws partly on principles of trademark law and partly on the approach in the Consumer and Investor Access Bill.

In this respect, Professor Conley goes too far by identifying the copying of database contents per se without a concurrent use or distribution of those contents in commerce as an activity that a database producer would seek to prohibit. Though Professor Conley may be correct in proposing that a rationally self-interested database producer would want to prohibit copying per se, this concern likely owes more to the influence of copyright law on database protection initiatives than to any realistic commercial concerns of database producers.

Even a model based on limiting the definition of a database to the commercial field would likely require some public policy permitted uses enhanced by a compulsory licensing program. ${ }^{299}$ However, focusing on commerce and registration of commercial interests should make it easier to carve out these exceptions when compared with the current models of database protection legislation.

To accommodate such permitted uses, the law should ensure that permited activities cannot be effectively precluded by contract or technological protection measures. The ability of the administrative body to order the release of certain information or to make a compulsory licensing order could minimize problems with contractual or technological protection measures. $^{300}$

\section{G. The Administrative Body}

For the law to work, it must establish an expert administrative body to oversee the registration of database rights, the compulsory licensing of

298. Brown, Bryan, \& Conley, supra note $40,934$.

299. See Austin, supra note 52, 787.

300. Cohen, supra note $65,607-09$ (noting that public policy considerations may be used to support legislation that overrides contract and technological protection measures in relation to digital information products). 
database contents, ${ }^{301}$ and the release of database contents into the public domain. This body would require experts from database-utilizing sectors in science, technology, education, and commerce.

An administrative body would have the advantage of a clear and centralized focus on database issues, allowing it to develop expertise in this area. This centralizing function should promote consistency and efficiency when deciding database issues.

For example, the centralization created by the Uniform Dispute Resolution Policy ("UDRP") ${ }^{302}$ for Internet domain name disputes has streamlined disputes that were tried in a variety of national fora, applied different laws, and often created inconsistent results. ${ }^{303}$

The domain name dispute resolution procedure is not a perfect analogy to the database scheme suggested here. The UDRP is international in scope and administered by private bodies such as the Internet Corporation for Assigned Names and Numbers ("ICANN"), acting through intentional agents such as WIPO. Furthermore, the UDRP is limited to the resolution of disputes and does not deal with issues such as whether a domain name can be registered in the first place. ${ }^{304}$ However, the UDRP does illustrate the potential efficiency benefits of centralizing controversial issues relating to a particular class of digital information assets in a body that can gradually develop an expertise in the area. ${ }^{305}$

301. A detailed discussion of the precise situations in which compulsory licensing might be allowed/required is beyond the scope of this preliminary discussion into changing the basic direction of the database protection debate. However, it does seem that whatever model of database protection legislation is ultimately brought into play (if any), there needs to be some possibility of compulsory licensing certainly in the case of sole source information providers and arguably in some other situations where the database protection legislation is causing practical results that are undesirable as a matter of public policy. One example might be in the difficult area of scientific and educational databases that often have competing commercial and non-commercial applications. The availability of an expert administrative body that might decide questions relating to the possibility of compulsory licensing in such cases could be a valuable addition to/improvement on some of the previously discussed models for database protection legislation.

302. INTERNET CORP. FOR ASSIGNED NAMES \& NUMBERS, UNIFORM DISPUTE RESOLUTION POLICY, available at http://www.icann.org/dndr/udrp/policy.htm (last visited May 11, 2003) [hereinafter UDRP].

303. See LEMLEY ET AL., supra note 13, at 676-82 (describing the operation of the UDRP).

304. UDRP, supra note 302 , cl. 3.

305. In actual fact, the dispute resolution functions under the UDRP are currently concentrated in three distinct bodies authorized by ICANN to hear domain name 
In fact, an administrative entity specializing in database issues could also hear, as an alternative to litigation, disputes involving rights in databases. This would have the advantages usually associated with alternative forms of dispute resolution such as reduced cost, the expertise of people hearing the dispute, and perhaps confidentiality and informality. ${ }^{306}$ Presumably, as with the UDRP, such a system would not be able to oust the court's jurisdiction entirely. ${ }^{307}$ However, some disputes could be kept out of court if those with registered databases were required to submit to an administrative proceeding before starting litigation on a database dispute.

Collecting database disputes together in one place, at least initially, could also minimize inconsistent interpretation of the legislation by different courts. This would encourage judges to examine the reasoning of the administrative body before making judicial determinations on the same or similar fact situations. Thus, in a database dispute resolution system along the lines suggested here, the administrative determinations should be published to aid judges, assuming, of course, that the administrative proceedings in question are not confidential in nature. The initial debates about the establishing the framework for the administrative system would determine whether such proceedings would be confidential.

\section{H. Unregistered Databases}

As with trademark law, a new database law should specify the legal position on non-registered databases used in commerce. This could follow the trademark model and permit developers of unregistered databases to protect them under other laws (such as contract, copyright, or trade secret) where applicable, but deny protection under the sui generis law. ${ }^{308}$

It may also be a good idea for the legislation to require or advise owners of registered database rights to include registration details on their databases, giving others notice of the existence of the rights. ${ }^{309}$ Failure to

disputes. However, the WIPO arbitration panel does hear the majority of disputes and so is an important centralizing force here.

306. See, e.g., Richard GaRnett ET Al., A Practical Guide to InTERnational COMMERCIAL ARBITRATION 11-14 (2000).

307. UDRP, supra note 302 , cl. 4(k) (preserving the parties' rights to litigate a domain name dispute subsequent to the administrative proceeding).

308. An example of such a model can be found in the United Kingdom trademarks legislation. The 1994 Trade Marks Act provides that, although common law (unregistered) marks are not protected under the legislation, nothing in the Act affects law relating to the tort of "passing off" with respect to protecting unregistered trademarks. See Trade Marks Act, 1994, § 2(2) (Eng.).

309. Wolken, supra note 67, at 1296. 
give notice could result in loss of statutory protection for the rights. Again, this places a strong onus on those seeking legal protection to take reasonable steps to protect the intellectual property rights they wish to assert in their work. In this way, the law would provide incentives to registered database holders that incorporate technological protection measures such as digital watermarks into their databases. ${ }^{310}$

\section{Benefits of Database Law Reform}

Drafting a model database law using the methods discussed above has several advantages over existing legislation. For example, clearly restricting the concept of a protected database to those databases developed for commercial purposes would be beneficial. This will focus the law on realistic commercial objectives and will lessen the focus on often-problematic fair use provisions. Furthermore, using a registration system for commercial databases will help to clarify who owns what rights and in what markets. It will create greater clarity and certainty in database proprietorship and in permitted activities in databases.

Another benefit would be the establishment of a specialist administrative body to oversee database registration, commercial disputes, and requests to release database contents. Such an approach would focus and centralize issues relating to databases, taking those issues outside the realm of pure market control. Whatever problems there might be with a centralized administrative body, reliance on pure market forces would not likely achieve better results, particularly in protecting the public domain and individual competing interests in information.

Any new database law should not derogate from pre-existing intellectual property rights that may apply to a database, such as copyright in the selection or arrangement of contents of a particular database. ${ }^{311}$ The rights embodied in the new law should be distinct from existing intellectual property rights and should be able to co-exist without interfering with the balance of other intellectual property laws. ${ }^{312}$

310. See MacQueen, supra note 290.

311. CDPA, supra note 80, §3A(2); Feist Publ'ns v. Rural Tel. Serv. Co., 499 U.S. 340,340 (1991).

312. It has been clearly accepted in the past that different intellectual property rights can co-exist in the same item at the same time; they simply protect different attributes of the item in question. This model has been adopted in the United Kingdom with respect to rights in databases as a result of, the E.U. Directive. The English legislation specifically contemplates that a database right and a copyright may co-exist in the same database at the same time and will simply protect different aspects of the database. CRDR, supra at note 254, R. 13(2). 


\section{THE INTERNATIONAL DIMENSION}

\section{A. The International Picture on Database Protection}

Whether or not the proposed solution would be attractive to the United States, efficient database protection legislation faces a greater problem: globalization. Now that many electronic databases are easily accessible internationally, the U.S. approach to database protection will impact and be affected by the international sphere. The European Union has already enacted database protection legislation that gives broad proprietary protection to database contents but without sufficient public policy exceptions or government oversight. ${ }^{313}$ Canada has no database protection legislation but will likely carefully watch the United States and the European Union. As noted above, Australia appears to rely on copyright protection for databases.

If other countries enact database legislation based on the E.U. approach, international harmonization may be achieved. But this could sacrifice significant aspects of the public domain and interfere with the traditional intellectual property framework. On the other hand, if countries like the United States and Canada enact legislation that is out of step with the European Union, the E.U. Member States may have to reconsider their approach to database protection in order to achieve international harmonization. ${ }^{314}$

Perhaps the most important step here is to finish an international treaty on database protection that can be adopted by jurisdictions throughout the world. ${ }^{315}$ However, to do so, we must reach consensus on the best way to balance the many rights, liabilities, and exceptions that would form database protection. ${ }^{316}$ Thus, these issues should be debated further, particularly between the United States and the European Union, to arrive at a model that achieves an appropriate balance between protecting commercial activities and preserving the public domain. In addition, we must maintain the traditional aims of intellectual property protection; encouraging innovation while protecting the public domain for the advancement of arts and sciences.

Arguably, the European Union has already taken up this debate, but perhaps with insufficient input from the scientific and educational

313. Colston, supra note $12, \S \S 1,2.2$; Reichman \& Samuelson, stupra note 9 , at 5556; Reichman \& Uhlir, supra note 29 , at 829.

314. Colston, supra note $12, \S \S 5,5.2$.

315. Davison, supra note 130, at 283-84.

316. See Reichman \& Samuelson, supra note 9, at 138. 
sectors. ${ }^{317}$ The lack of widespread international acclaim for the European Union's current solution further supports the need for revision. Indeed, the operation of the E.U. Directive was supposed to be reviewed in $2002 .{ }^{318}$ However, this review has not taken place. There is also supposed to be a forthcoming WIPO report on database protection that takes into account the experiences to date of database protection in the European Union. ${ }^{319}$

\section{B. The Role of International Legislative Cooperation}

To achieve international consensus on database protection, states may need to re-draft or amend legislation already in force throughout the European Union in order to attain a degree of international harmonization. ${ }^{320}$ This may be politically difficult, but could prevent the currently inadequate database laws from stymieing international commerce.

Many interrelated questions are raised when trying to determine an appropriate level of national and international protection for databases. First, how harmonized must the law be internationally and among jurisdictions in a federal system like the United States, Canada, and Australia? ${ }^{321}$ For example, would it cause widespread international conflict for non-E.U. countries to take an approach different than the E.U. Directive but nevertheless to operate alongside its provisions? ${ }^{322}$ If other countries favor the model this Article proposes, this integration may prove problematic.

Second, should the form of protection be proprietary or nonproprietary? Does it make a difference? Broad proprietary protections, tempered with detailed exceptions and subject to contractual and technological limitations, may offer no greater protection than narrow quasi-proprietary protections with fewer exceptions. ${ }^{323}$ This question may be misplaced. The better focus is on commercial uses of databases

317. Id. at 139.

318. Colston, supra note $12, \S \S 5,5.2$.

319. Id. As noted above, the issue of intellectual property protection for non-original databases is back on the agenda for the WIPO committee on Copyright and Related Rights.

320. Colston, supra note $12, \S \S 5,5.2$.

321. The need to harmonize within a federal jurisdiction is usually not too difficult to satisfy if the measures taken remain in the realm of intellectual property law as this tends to be a matter within federal legislative competence in most federal jurisdictions. Some jurisdictions may need to use federal commerce powers rather than intellectual property powers in this area.

322. Colston, supra note $12, \S 6$.

323. Davison, supra note 130 , at 283-84. 
regardless of whether the legislation adopts proprietary terminology. Registration of database rights for markets could also provide an important (if costly) innovation here. Registration could perhaps work at the international level, either through a series of electronically linked domestic registers or an international register.

Third, is it possible to create appropriate protection for databases without unjustifiably interfering with the traditional societal intellectual property bargain? Any new legislative scheme should recognize the need for a strong and vibrant public domain of information and ideas. Any legislative model that ultimately gains acceptance as the international standard should incorporate some safeguards that protect this public domain. These safeguards may include compulsory licensing or the loss of protection where public policy requires all or part of the information to be released into the public domain. Indeed, governments may need to more actively protect the public domain than they have under previous law.

Fourth, do the legislatures have the competence to enact appropriate legislation? For example, if new database protection does not fall within the U.S. Constitution's Arts and Sciences or Commerce clauses, ${ }^{324}$ database protection would have to be attempted as uniform state law, which is contentious and not easy to achieve. Canada and Australia may face similar issues. However, if the federal legislature can be used to support database protection, these issues will not arise. In the United States, opinions divide on whether the Commerce clause can support database protection legislation. ${ }^{325}$ Under the Commerce clause, legislation that creates a new intellectual property right that does not promote the progress of the arts and sciences may not be justifiable. Indeed, the Executive Summary of the United States Copyright Office's report on the Legal Protection for Databases in 1997 commented on this problem:

If database legislation appears to be the equivalent of copyright under another name, but providing protection to uncopyrightable subject matter for unlimited times, the use of a different label and the recitation of a different constitutional basis will not alone be sufficient to save it. To the extent that the legislation promotes different policies from copyright, and does so in a different manner, it is similar to trademark law, and therefore seems likely to survive a constitutional

324. Austin, supra note 52, 189 ; see also Benkler, supra note 32, at 412-13; Pollack, supra note 121 .

325. U.S. COPYRIGHT OFF., supra note 100, at xviii; Pollack, supra note 121. 
challenge. The more the statute differs from copyright, the more likely it is to be constitutional. ${ }^{326}$

This distinction between copyright and trademark law further supports a model for database protection legislation in the United States that moves away from existing copyright law and towards trademark law. Such a scheme would lessen the risk that the law would be found unconstitutional for trying to create a broader version of copyright under a different constitutional head of power.

Fifth, should the law bolster technological protections put into place by database makers to restrict or prevent access to a database? Such bolstering would be similar to what the DMCA did for copyright in the United States. ${ }^{327}$ Technological protection and encryption measures will be a useful tool for database producers seeking to prevent unauthorized access to database contents. However, given the criticisms of the DMCA's approach to legally bolstering these protections, ${ }^{328}$ perhaps this is not the right approach for sui generis database protection legislation.

Sixth, how should any new law deal with inter-jurisdictional problems like having a defendant in another jurisdiction? Could the law deal with situations like the inability to identify the wrongful appropriator of database contents because of anonymous online access? Since notice of a database property right can bind third parties, it would be relatively easy under a proprietary law for a right-holder to identify those wrongfully using its databases in commercial competition, regardless of how that competitor came by those products in the first place. ${ }^{329}$ The ability to

326. U.S. COPYRIGHT OFF., supra note 100 , at xviii.

327. Article 10 of the draft WIPO treaty on database protection suggests that database protection legislation should include provisions that make it unlawful to import, manufacture or distribute devices that can defeat such technological protections. See WIPO, Draft Treaty, supra note 86 , art. 10; see also supra note 251 and accompanying text. Interestingly, the Draft Treaty remains silent on the question of conduct that actually circumvents a technological protection measure-it concentrates instead on trafficking in devices that could be used to circumvent a technological protection measure. This is a somewhat more limited approach than that taken under the DMCA in relation to the circumvention of technological measures designed to protect copyright works.

328. Benkler, supra note 32, at 414-29; Nimmer, supra note 33, at 720-26; Samuelson, supra note 33, at 537-38.

329. Provided that a third party has notice of the property right, it should be held accountable for its unauthorized conduct in relation to the relevant property, provided that it has no other legal excuse for its conduct, such as a public interest upheld by the relevant administrative body. Notice of a database right is provided by registration and database owners could also be required to display their registered status prominently on their database. 
identify such wrong-doers would be increased by using technological measures like digital watermarking to identify the original source of database contents but cross-jurisdictional enforcement may be problematic.

All of these questions are difficult to address in practice. It is unfortunate that the WIPO Database Treaty ${ }^{330}$ was not completed in 1996 when the Copyright Treaty ${ }^{331}$ and Performances and Phonograms Treaties $^{332}$ were completed. Such an agreement would have given guidance for tackling these issues at the international level. The current draft of the treaty is vague. The term of protection to be granted to a database maker is also unclear with a number of options given in the current text. ${ }^{333}$ The WIPO Database Treaty requires further debate and redrafting, particularly on the nature of the rights that should be granted to database makers and the necessary exceptions to those rights.

Much work must be done before we can create effective harmonized laws that meet the needs of the global information society. The debate may become clearer if we ignore the question whether databases should be protected as property and instead focus on how to clearly delimit the rights and obligations of those who have developed commerical databases. At the international level, the important issues are (a) how to achieve international consensus and what that consensus should entail; (b) how to determine the level of uniformity needed to support harmonized international database law; $;^{334}$ and (c) how to effectively translate any

330. See supra notes 86,251 and accompanying text.

331. Copyright Treaty, Dec. 23, 1996, World Intellectual Property Organization CRNR/DC/94, available at http://www.wipo.org/eng/diplconf/distrib/94dc.htm (last viewed on Aug. 30, 2003).

332. WIPO Performances and Phonograms Treaty, Dec. 23, 1996, World Intellectual Property Organization CRNR/DC/95, available at http://www.wipo.org/eng/diplconf/ distrib/95dc.htm (last viewed on Aug. 30, 2003).

333. The current draft Article 8 of the treaty suggests the options of a twenty-year or a fifteen-year term of protection. See WIPO, Basic Proposal for the Substantive Provisions of the Treaty on Intellectual Property in Respect of Databases to be Considered by the Diplomatic Conference (on file with author), available at http://www .wipo.org/eng/diplconf/6dc_a08.htm (last visited Sept. 26, 2001). As noted above, even a fifteen-year term of protection is arguably unreasonably long.

334. It should be noted that "harmonization" does not necessarily connote complete uniformity. It is used here to refer to laws that can work together without too many practical conflicts, even if the laws are not framed in precisely the same terms and maybe are not even framed with the exact same theoretical underpinnings in mind. In the database context, the possibility of relatively harmonized, yet not uniform, law is contemplated in Colston, supra note 12. 
resulting international policies or treaty obligations into harmonized national laws.

We need significant international consensus and guidance on these issues, which could be done through WIPO or UNCITRAL. ${ }^{335}$ Thus, a final version of the WIPO treaty on database protection could be a first step in reaching consensus, although this may require some amendment of both the E.U. Directive and the E.U. Member State's national legislation implementing the Directive.

If the United States, either nationally or through WIPO, can present some new models that appear to streamline the process, other jurisdictions may be prepared to adjust their current positions on database protection. A modified E.U. model could even work alongside a somewhat different model in the United States provided that the two approaches maintain compatible administrative and enforcement mechanisms.

\section{International Treaty Goals}

For an international database protection treaty, issues that warrant consideration include (a) the nature and scope of legal rights for databases with commercial uses; (b) distinguishing between sui generis database rights and existing copyright protection for databases and compilations; (c) the nature and scope of exceptions for private, scientific, educational, and research use; and, (d) the an administrative body overseeing registration, compulsory licensing, and dispute resolution. ${ }^{336}$

The original draft WIPO database treaty started to resolve some of these issues on an international level, and the proposed study on the operation of current E.U. law would also help. However, to achieve the level of certainty required to enact meaningful and reasonably harmonized laws at the international level, decision makers must analyze the impacts of any database protection law on private, scientific, educational, and research uses. ${ }^{337}$ It must also consider whether standard domestic litigation is appropriate for the resolution of domestic and international disputes or whether litigation should be augmented by specially tailored alternative dispute resolution administered by national or international experts.

335. UNCITRAL is the core body within the United Nations that deals with international trade issues. It coordinates the drafting of international treaties on matters affecting international trade. More information on UNCITRAL and its activities can be found at http://www.uncitral.org/en-index.htm (last visited June 19, 2002).

336. These might be established at the international level, or possibly through cooperative domestic initiatives.

337. Reichman \& Samuelson, supra note 9, at 114; Wolken, supra note 67, at 1297. 


\section{CONCLUSION}

In sum, to develop new database protection legislation that protects the public interest and promotes private enterprise in the global digital commons, we must distance the legislation's substantive rights and administration from pre-existing approaches like copyright law. The legislation should focus on database producers' clearly established and realistic commercial needs in order to significanly limit the scope of private database rights. Furthermore, the legislation should create a new specialist administrative body to oversee database rights and resolve issues surrounding the registration of databases, compulsory licensing, database dispute resolution, and the release of database contents into the public domain.

Legislation based on the model outlined in this article would have several advantages. First, database rights could be specifically tailored to the realistic needs of commercial database producers. Second, these needs could be balanced against community concerns over the overcommodification of information. Third, constitutional concerns would arise less often because the law would not focus, like a new form of copyright, on protecting creators of information works but would focus instead on regulating commercial activity.

Establishing a specialized administrative body overseeing database protection would also be helpful. Such a body would ultimately develop centralized expertise on the database industry. And by taking input not only from commercial but scientific, technical, and educational groups, the body could tailor registration and dispute resolution procedures to the 'realistic needs of different sectors of society.

A successful test of this model in the United States could serve as a template for international approaches to database protection. It may even convince members of the European Union that such a model would work better than the E.U. Directive. If E.U. members are open to making changes in line with such a model, the possibility of international harmonization across jurisdictions would be greatly enhanced. This harmonization would benefit large sectors of industry that increasingly revolve around international information commerce.

Indeed, the global community must rethink approaches to sui generis database protection legislation. For example, the property concept itself can be applied to databases in order to strike an appropriate balance between private rights and public interests in databases. The United States has an opportunity to become a global leader in providing effective and efficient solutions to problems involving the legal protection of databases. 
Rather than continuing to argue about whether or not we should advocate property in in these valuable information compilations, we should move the debate to another level by advocating the use of property rights to create a balanced system of private rights and public responsibilities.

Looking long-term, any experiment using database property rights to balance different interests may prove a useful template for approaching the regulation of digital information generally. Database rights may be the tip of the iceberg; the next logical development being a body of "information law" or "information property law" that balances competing interests in information in general. Indeed, thinking about new ways of conceptualizing legal property rights in databases may help us to reconceptualize ideas about information property, broadly and globally. 